\title{
Endo-lysosomal $\mathrm{A} \beta$ concentration and $\mathrm{pH}$ enable formation of $\mathrm{A} \beta$ oligomers that potently induce Tau missorting
}

Marie P. Schützmann ${ }^{1, \dagger}$, Filip Hasecke ${ }^{1, \dagger}$, Sarah Bachmann², Mara Zielinski ${ }^{3}$, Sebastian Hänsch $^{4}$, Gunnar F. Schröder ${ }^{3,5}$, Hans Zempel ${ }^{2}$, and Wolfgang Hoyer ${ }^{1,3, *}$

${ }^{1}$ Institut für Physikalische Biologie, Heinrich-Heine-Universität Düsseldorf, 40204

Düsseldorf, Germany

${ }^{2}$ Institute of Human Genetics and Center for Molecular Medicine Cologne (CMMC), University of Cologne, Faculty of Medicine and University Hospital Cologne, 50931

Cologne, Germany

${ }^{3}$ Institute of Biological Information Processing (IBI-7) and JuStruct: Jülich Center for Structural Biology, Forschungszentrum Jülich, 52425 Jülich, Germany

${ }^{4}$ Department of Biology, Center for Advanced Imaging (CAi), Heinrich-Heine-Universität Düsseldorf, 40204 Düsseldorf, Germany

${ }^{5}$ Physics Department, Heinrich-Heine-Universität Düsseldorf, 40204 Düsseldorf, Germany Correspondence and requests for materials should be addressed to W.H. (email: wolfgang.hoyer@hhu.de) 


\begin{abstract}
Amyloid- $\beta$ peptide $(A \beta)$ forms metastable oligomers $>50 \mathrm{kD}$, termed $A \beta O$ s or protofibrils, that are more effective than $\mathrm{A} \beta$ amyloid fibrils at triggering Alzheimer's disease-related processes such as synaptic dysfunction and Tau pathology, including Tau mislocalization. In neurons, $\mathrm{A} \beta$ accumulates in endo-lysosomal vesicles at low $\mathrm{pH}$. Here, we show that the rate of $\mathrm{A} \beta \mathrm{O}$ assembly is accelerated 8,000-fold upon $\mathrm{pH}$ reduction from extracellular to endolysosomal $\mathrm{pH}$, at the expense of amyloid fibril formation. The $\mathrm{pH}$-induced promotion of $\mathrm{A} \beta \mathrm{O}$ formation and the high endo-lysosomal $\mathrm{A} \beta$ concentration together enable extensive $\mathrm{A} \beta \mathrm{O}$ formation of $\mathrm{A} \beta 42$ under physiological conditions. Exploiting the enhanced $\mathrm{A} \beta \mathrm{O}$ formation of the dimeric $A \beta$ variant $\operatorname{dim} A \beta$ we furthermore demonstrate targeting of $A \beta O$ s to dendritic spines, potent induction of Tau missorting, a key factor in tauopathies, and impaired neuronal activity. The results suggest that the endosomal/lysosomal system is a major site for the assembly of pathomechanistically relevant A $\beta O s$.
\end{abstract}

\title{
Introduction
}

$\mathrm{A} \beta$ amyloid fibrils are highly stable protein aggregates of regular cross- $\beta$ structure that constitute the main component of the senile plaques in the brains of Alzheimer's disease (AD) patients $^{1-3}$. Although amyloid fibrils can exert toxic activities, metastable $\mathrm{A} \beta$ oligomers are thought to represent the main toxic species in $\mathrm{AD}^{3-5}$. At sufficiently high monomer concentration, $\mathrm{A} \beta$ readily forms oligomers with molecular weights $>50 \mathrm{kD}$ with spherical, curvilinear, and annular shapes, where the elongated structures appear as "beads-on-a-string"like assemblies of spherical oligomers ${ }^{4-11}$. While multiple names have been given to these metastable $\mathrm{A} \beta$ oligomers, including $\mathrm{A} \beta \mathrm{O}$, $\mathrm{ADDLs}$, and protofibrils, they seem to be closely related with regard to their structures and detrimental activities, and likely form along a common pathway ${ }^{6,7,12}$. Importantly, this pathway is distinct from that of amyloid fibril formation, i.e., $\mathrm{A} \beta \mathrm{O}$ s are not intermediates on the pathway to amyloid fibrils (they are "off- 
pathway") but constitute an alternative $\mathrm{A} \beta$ assembly type with distinct toxic activities (Fig.

1a) ${ }^{4,5,11,13}$. The distinct nature of $A \beta$ amyloid fibrils and $A \beta O$ s is also reflected in their different formation kinetics. $A \beta$ amyloid fibrils form by nucleated polymerization with crucial contributions from secondary nucleation processes, resulting in the characteristic sigmoidal growth time courses that feature an extended lag-time ${ }^{14}$. A $\beta O$ s, on the other hand, form in a lag-free oligomerization reaction that has a substantially higher monomer concentration dependence than amyloid fibril formation ${ }^{11}$.

Several lines of evidence support a critical role of $A \beta O$ s in $A D$ pathogenesis. $A \beta O$ s of sizes $>50 \mathrm{kD}$ are the main soluble $\mathrm{A} \beta$ species in biological samples ${ }^{15}$. They are synaptotoxic, disrupt long-term potentiation, and cause cognitive impairment in mouse and non-human primate models ${ }^{4,8,16-22}$. Furthermore, A $\beta O s$ induce oxidative stress, endoplasmic reticulum stress, neuroinflammation, and elicit Tau missorting, the earliest hallmark of tauopathy in AD 20,22-28. The detrimental effects are enhanced by pathogenic $A \beta$ mutations that specifically promote $\mathrm{A} \beta \mathrm{O}$ formation, in particular the arctic $(\mathrm{A} \beta \mathrm{E} 22 \mathrm{G})$ and the Osaka $(\mathrm{A} \beta \Delta \mathrm{E} 22)$ mutations $^{21,22,27,29,30}$. Consequently, targeting A $\beta O$ s therapeutically is an important alternative to amyloid-centric approaches and has entered clinical evaluation ${ }^{31-33}$.

$\mathrm{A} \beta \mathrm{O}$ s were suggested to trigger toxic effects through ligand-like binding to a remarkably high number of candidate receptors ${ }^{4,34}$. A $\beta$ Os achieve clustering of receptors in cell surface signaling platforms, probably promoted by the multivalency inherent to $\mathrm{A} \beta \mathrm{Os}^{4,34,35}$. $\mathrm{A} \beta \mathrm{O}$ clustering is especially prominent at dendritic spines, which deteriorate upon prolonged exposure to $\mathrm{A} \beta \mathrm{Os}^{17}$. Importantly, this effect is mediated by Tau protein, providing a connection between the $\mathrm{A} \beta$ and the Tau aspects of $\mathrm{AD}$ pathogenesis. $\mathrm{A} \beta \mathrm{O}$ s induce missorting of Tau into the somatodendritic compartment as well as Tau hyperphosphorylation, leading to microtubule destabilization and spine $\operatorname{loss}^{22,36-38}$.

In addition to receptor binding of extracellular $A \beta O$, intracellular $A \beta O$ s are thought to contribute to AD pathogenesis ${ }^{39}$. The endosomal-lysosomal system is the main site not only 
for $A \beta$ production but also for the uptake of $A \beta$ monomers and $A \beta O$ s $^{26,40-47}$. A $\beta$ accumulates in endosomes/lysosomes, which promotes aggregation with potential consequences for cellular homeostasis as well as for the spreading of $A \beta$ pathology by exocytosis of aggregated A $\beta$ species $^{26,27,40,43-45,47-49}$.

At neutral $\mathrm{pH}$, high $\mathrm{A} \beta$ concentrations are required for $\mathrm{A} \beta \mathrm{O}$ formation. Widely-used protocols for $\mathrm{A} \beta \mathrm{O}$ preparation start from around $100 \mu \mathrm{M} \mathrm{A} \beta$ monomers ${ }^{7,8,10}$. At tenfold lower $\mathrm{A} \beta$ concentration, the formation of $\mathrm{A} \beta \mathrm{O}$ s is already greatly disfavored, which enables the investigation of the pure sigmoidal time course of amyloid fibril formation, including the analysis of on-pathway oligomer formation ${ }^{14,50,51}$. These on-pathway oligomers, however, are short-lived, rapidly consumed in the process of fibril formation, and, as evident from the different assembly kinetics, clearly distinct from the neurotoxic off-pathway A $\beta O$ s introduced above. To investigate $\mathrm{A} \beta \mathrm{O}$ formation, we have generated a dimeric variant of $\mathrm{A} \beta$ termed $\operatorname{dim} A \beta$, in which two $A \beta 40$ units are linked in one polypeptide chain through a flexible glycineserine-rich linker ${ }^{11}$. In $\operatorname{dim} A \beta$, the conformational properties of the $A \beta 40$ units are not altered as compared to free $A \beta 40$ monomers ${ }^{11}$. The linkage of two $A \beta$ units, however, increases the local $\mathrm{A} \beta$ concentration, which strongly promotes the highly concentration-dependent formation of $\mathrm{A}_{\beta} \mathrm{Os}^{11}$ (Fig. 1b,c). The advantages in applying $\operatorname{dim} \mathrm{A} \beta$ for the study of $\mathrm{A} \beta \mathrm{Os}$ are: First, A $\beta$ Os form already above a threshold concentration (critical oligomer concentration, COC) of $\sim 1.5 \mu \mathrm{M} \operatorname{dim} \mathrm{A} \beta$. Second, the increased local $\mathrm{A} \beta$ concentration preferentially accelerates $\mathrm{A} \beta \mathrm{O}$ formation as compared to $\mathrm{A} \beta$ fibril formation, resulting in an enhanced separation of the kinetic phases of $A \beta O$ and $A \beta$ fibril formation which facilitates analysis.

There is an apparent discrepancy between the obvious pathogenic relevance of $A \beta O$ s and the high $\mu \mathrm{M} A \beta$ concentrations required for $\mathrm{A} \beta \mathrm{O}$ formation at neutral $\mathrm{pH}$ in vitro, which exceeds the estimated pico- to nanomolar concentrations of extracellular A $\beta$ in normal brain by several orders of magnitude ${ }^{43}$. However, accumulation of $A \beta$ in the endo-lysosomal system was shown to result in micromolar $\mathrm{A} \beta$ concentrations in late endosomes and lysosomes ${ }^{43}$, 
suggesting that these acidic vesicles might be the prime sites of $A \beta O$ formation. Acidic conditions have been reported to accelerate $A \beta$ aggregation $^{52}$. Here, we applied $\operatorname{dim} A \beta$ and $\mathrm{A} \beta 42$ to test if $\mathrm{pH}$ reduction from neutral to endo-lysosomal $\mathrm{pH}$ affects $\mathrm{A} \beta \mathrm{O}$ formation. We find that endo-lysosomal $\mathrm{pH}$ in fact strongly accelerates $\mathrm{A} \beta \mathrm{O}$ formation, whereas amyloid fibril formation is delayed, suggesting that $\mathrm{A} \beta \mathrm{O}$ formation is the dominant aggregation process in endosomes/lysosomes. We furthermore show that $\operatorname{dim} A \beta$ is a disease-relevant model construct for pathogenic $A \beta O$ formation by demonstrating that $\operatorname{dim} A \beta A \beta O$ s target dendritic spines, induce AD-like somatodendritic Tau missorting, and reduce synaptic transmission in terminally matured primary neurons. This indicates that $\operatorname{dim} A \beta$-derived oligomers are suitable for the study of downstream mechanistic and neuropathological events in the progression of AD.

\section{Results}

\section{$\operatorname{DimA\beta }$ assembles into AßOs that bind to dendritic spines and potently induce tau} missorting

The assembly kinetics of $\operatorname{dim} \mathrm{A} \beta$ at neutral $\mathrm{pH}$ monitored by Thioflavin $\mathrm{T}$ (ThT) show a biphasic behavior above a concentration (COC) of $\sim 1.5 \mu \mathrm{M}$, with the first phase corresponding to the lag-free oligomerization into $\mathrm{A} \beta \mathrm{Os}$ and the second phase reflecting amyloid fibril formation $^{11}$ (Fig. 1b,c). DimA $\beta$ A $\beta$ Os are of spherical and curvilinear shape (Fig. 1c) and rich in $\beta$-structure ${ }^{11}$, in agreement with the characteristics of $A \beta O$ s formed from $A \beta 40$ and $A \beta 42$ (ref. ${ }^{4-6,9,13,20}$ ). We applied cryo-EM to further characterize $\operatorname{dim} A \beta \mathrm{A} \beta \mathrm{O}$ s structurally. As larger A $\beta$ Os seem to be assemblies of small spherical structures, our analysis focused on the smallest AßOs observed in the micrographs (Fig. 1d,e, Supplementary Figs. 1-3). We obtained a 3D density reconstruction (Fig. 1e) at a resolution of $17 \AA$ which shows a bowl-shaped structure with dimensions of $80 \times 48 \times 40 \AA$. From this reconstruction we were able to calculate the approximate molecular mass that fits into the density to be $62 \mathrm{kDa}$ (Supplementary Fig. 3; see 
Methods). Therefore, the smallest $\mathrm{A} \beta \mathrm{O}$ species, as visible on the micrographs, likely contains six $\operatorname{dim} A \beta$ monomers (total MW of $60.2 \mathrm{kD}$ ), which corresponds to twelve $\mathrm{A} \beta 40$ units. Dodecameric $A \beta$ oligomers were observed before in $A \beta O$ preparations from synthetic peptide or isolated from $\mathrm{AD}$ brain or mouse models, and have been associated with neuronal dysfunction and memory impairment ${ }^{53-56}$.

$\mathrm{A} \beta \mathrm{O}$ formation occurred on the same time scale in the plate reader experiment as in microcentrifuge tubes (Fig. 1b,c,f). In contrast, extensive amyloid formation was observed in the plate reader experiment after $\sim 10 \mathrm{~h}$, but was not detectable when $\mathrm{A} \beta \mathrm{O}$ s were incubated in microcentrifuge tubes for several days, unless the microcentrifuge tube was agitated (Fig. 1b,c,f). This suggests that the movement of the microplate in the plate reader, caused by scanning of the wells during measurements every 3 minutes and 2 seconds of preceding orbital shaking, creates sufficient agitation to promote amyloid fibril nucleation. When the samples in the microplate were covered with a layer of mineral oil, $\mathrm{A} \beta \mathrm{O}$ formation was unaffected but amyloid fibril formation was completely abrogated (Supplementary Fig. 4), in line with the essential role of the air-water interface in $\mathrm{A} \beta$ amyloid formation in vitro ${ }^{57}$. The strong effects of agitation ${ }^{14}$ and air-water interface on $\mathrm{A} \beta$ amyloid fibril formation but not on $\mathrm{A} \beta \mathrm{O}$ formation confirms again that their assembly mechanisms are different, and is in line with the notion that $\mathrm{A} \beta \mathrm{O}$ formation does not involve a nucleation step ${ }^{11,58}$. When $\mathrm{A} \beta \mathrm{Os}$, formed by incubation of $\operatorname{dim} \mathrm{A} \beta$ above the COC, were diluted to sub-COC concentrations, they persisted for $>24$ hours, indicating high kinetic stability (Supplementary Fig. 5). We conclude that A $\beta O$ s formed from $\operatorname{dim} \mathrm{A} \beta$ under quiescent conditions are kinetically stable, not replaced by amyloid fibrils for several days, and can be applied at sub- $\mu \mathrm{M}$ concentrations. DimA $\beta$ A $\beta$ Os may therefore serve as a favorable $\mathrm{A} \beta \mathrm{O}$ model.

To test if $\operatorname{dim} A \beta A \beta O$ s cause the same biological effects as reported for $A \beta O$ s formed from $\mathrm{A} \beta 40$ or $\mathrm{A} \beta 42$, we investigated their binding to dendritic spines, their direct cytotoxicity, their capacity to induce Tau missorting, and their consequences for neuronal function. A $\beta O$ s were 
formed from $20 \mu \mathrm{M} \operatorname{dim} A \beta$ and added to primary mouse neurons (DIV15-22) to a final concentration of $0.5 \mu \mathrm{M}$ (all $\operatorname{dim} \mathrm{A} \beta \mathrm{A} \beta \mathrm{O}$ concentrations given in $\operatorname{dim} \mathrm{A} \beta$ equivalents). $1 \mu \mathrm{M}$ A $\beta 40$ was used as monomeric control. DimA $\beta$ localized to neuronal dendrites both after 3 and 24 hours of treatment, where it partially co-localized with dendritic protrusions positive for filamentous actin (stained by phalloidin), which mark synaptic spines (Fig. 2a). In contrast, A 340 monomers did not show substantial localization to dendrites (Fig. 2a). Direct cytotoxicity was tested by analysis of the sizes and shapes of neuronal nuclei upon staining with NucBlue. The fractions of normal and dense nuclei did not change significantly after incubation with $\operatorname{dim} \mathrm{A} \beta \mathrm{A} \beta \mathrm{Os}$ (Fig. 2b), indicating the absence of direct cytotoxicity, in line with previous reports on $\mathrm{A} \beta \mathrm{Os}^{59}$.

Tau cellular distribution was analyzed with an anti-Tau (K9JA) antibody. DimA $\beta$ treated neurons showed strong enhancement of the fluorescence signal of Tau in the soma after 24 hours of treatment (Fig. 3), indicating pathological somatodendritic Tau missorting as previously reported for $A \beta O \mathrm{~s}^{37,38}$. In contrast, $\mathrm{A} \beta 40$ monomers did not induce Tau missorting in our experimental setting (Fig. 3). In previous studies, Tau missorting and spine loss were reversible within 12-24 hours due to loss of $\mathrm{A} \beta \mathrm{O}$ potency (transformation of $\mathrm{A} \beta \mathrm{Os}$ over time to larger, non-toxic aggregates $)^{37,60}$. Here, we observe an increase of Tau missorting over time, which indicates remarkable kinetic stability and persistent activity in terms of capacity to induce AD-like Tau missorting of $\operatorname{dim} A \beta \mathrm{A} \beta \mathrm{O}$.

Next, we investigated the consequences of $\mathrm{A} \beta \mathrm{O}$ exposure for neuronal function. As readout, we measured spontaneous calcium oscillations in our neuronal cultures after $\mathrm{A} \beta \mathrm{O}$ treatment as an indicator for neuronal activity with live-imaging, using the fluorescent cell permeable calcium indicator Fluo4 as previously described ${ }^{37}$. A significant decrease of calcium oscillations was observed after $24 \mathrm{~h}$, but not after $3 \mathrm{~h}$, of treatment with $\operatorname{dim} A \beta$ A $\beta O$ s (Fig. 4). As calcium oscillations in our conditions depend on action potentials and neurotransmission, this indicates that $\operatorname{dim} \mathrm{A} \beta \mathrm{A} \beta \mathrm{O}$ s impair neuronal function. With regard to dendritic spine 
binding, lack of direct cytotoxicity, potent induction of Tau missorting as well as decreased neuronal activity, $\operatorname{dim} A \beta \mathrm{A} \beta \mathrm{O}$ s thus faithfully reproduce the observations made for $\mathrm{A} \beta \mathrm{O}$ formed from $A \beta 40$ or $A \beta 42$, or from 7:3 $A \beta 40: A \beta 42$ mixtures regarded as particularly toxic ${ }^{37}$. Of note, $\operatorname{dim} \mathrm{A} \beta \mathrm{A} \beta \mathrm{O}$ s effects appeared later (24h vs. $3 \mathrm{~h})$ than for the previously studied oligomers, hinting towards their kinetic and structural stability in cell culture conditions.

\section{A $\beta 42$ monomers as well as $\operatorname{dim} A \beta A \beta O s$ accumulate within endo-lysosomal compartments}

Next, we aimed to test the uptake of $\operatorname{dimA} \beta \mathrm{A} \beta \mathrm{O}$ s in neuronal cells. First, SH-SY5Y neuroblastoma cells were subjected to $100 \mathrm{nM}$ HiLyte Fluor 647-labeled A $\beta 42$. After 24 hours of incubation $A \beta 42$ accumulated within vesicular foci within the cytoplasm of the cells. Costaining with a LysoTracker dye showed prominent colocalization suggesting the accumulation of A 342 within endo-lysosomal compartments (Fig. 5a). This was in line with findings of previous studies that showed A 342 accumulation in acidic vesicles of neuroblastoma cells and

primary murine cortical neurons ${ }^{40,43-45}$. Hu et al. measured local A $\beta 42$ concentrations higher than 2.5 $\mu \mathrm{M}$ within endo-lysosomal compartments which exceeds the extracellular concentration by approximately four orders of magnitude ${ }^{43}$.

In a second attempt, SH-SY5Y cells were treated with Abberior Star 520SXP-labelled $\operatorname{dim} \mathrm{A} \beta \mathrm{A} \beta \mathrm{O}$ s revealing a similar colocalization in acidic vesicles (Fig. 5b). This confirms that both $\mathrm{A} \beta$ monomers and $\mathrm{A} \beta \mathrm{O}$ s are readily taken up by neuron-like cells and accumulate in the endo-lysosomal system.

\section{Endo-lysosomal pH promotes A $\beta O$ assembly but delays amyloid fibril formation}

Due to the accumulation of $A \beta$, endosomes/lysosomes might constitute the dominant site of the highly concentration-dependent $\mathrm{A} \beta \mathrm{O}$ formation. Apart from the increased $\mathrm{A} \beta$ concentration in endosomes/lysosomes, the low $\mathrm{pH}$ in late endosomes ( 5.5) and lysosomes ( 4.5) might promote $\mathrm{A} \beta \mathrm{O}$ formation. We used $\operatorname{dim} \mathrm{A} \beta$ to simultaneously determine the specific 
effects of $\mathrm{pH}$ on $\mathrm{A} \beta \mathrm{O}$ formation and on amyloid fibril formation. Lyophilized $\operatorname{dim} \mathrm{A} \beta$ was dissolved in $6 \mathrm{M}$ buffered guanidinium chloride, followed by size-exclusion chromatography (SEC) into $1 \mathrm{mM} \mathrm{NaOH}$, leading to a $\mathrm{pH}$ of 10.9 , and added to the wells of a microplate. The basic $\mathrm{pH}$ conditions prohibit premature aggregation of $\mathrm{A} \beta^{61}$. The $\mathrm{pH}$-dependent aggregation reaction was initiated in the microplate reader by injection of a 10x buffer yielding the desired final $\mathrm{pH}$, allowing for monitoring of ThT fluorescence without any substantial delay. We determined the kinetics of $\operatorname{dimA} \beta$ assembly between $\mathrm{pH} 4.8$ and 7.6 in the concentration range $0.65-5.0 \mu \mathrm{M}$. At neutral $\mathrm{pH}$, the initial kinetic phase reflecting $\mathrm{A} \beta \mathrm{O}$ formation spanned several hours, but upon $\mathrm{pH}$ reduction $\mathrm{A} \beta \mathrm{O}$ formation was continuously accelerated and occurred within a few seconds at $\mathrm{pH} 4.8$ (Fig. 6a-g). ThT fluorescence intensity decreased at acidic $\mathrm{pH}^{62}$, but was still sufficiently sensitive to detect the signal of $\mathrm{A} \beta \mathrm{O}$ formation at $\mathrm{pH} 4.8$ and $0.65 \mu \mathrm{M}$ $\operatorname{dim} \mathrm{A} \beta$ (Fig. $6 \mathrm{~g}$ ). For $\mathrm{pH} 7.4$, we have previously shown that a global fit of an $n^{\text {th }}$-order oligomerization reaction to the concentration-dependent assembly kinetics is in good agreement with the data and yields a reaction order of $\sim 3.3$ for $\operatorname{dim} \mathrm{A} \beta \mathrm{A} \beta \mathrm{O}$ formation ${ }^{11}$. Here, we found that a reaction order of 3 applied to global fitting of the concentration-dependent data results in fits that reproduce the kinetic traces at all $\mathrm{pH}$ values (Fig. 6a-g). This indicates that the fundamental mechanism of $\mathrm{A} \beta \mathrm{O}$ formation is not affected by $\mathrm{pH}$ reduction. A logarithmic plot of the obtained oligomerization rate constants against $\mathrm{pH}$ shows a linear trend with a slope of 1.56, i.e., the rate constant decreases 36 -fold per $\mathrm{pH}$ unit within the investigated $\mathrm{pH}$ range (Fig. 6h). At $\mathrm{pH} 4.8$, in between lysosomal and endosomal $\mathrm{pH}, \mathrm{A} \beta \mathrm{O}$ formation is 7,900-fold faster than at interstitial $\mathrm{pH}(7.3)$.

$\mathrm{A} \beta \mathrm{O}$ s formed at different $\mathrm{pH}$ values were imaged by AFM (Fig. 6i). From $\mathrm{pH} 7.6$ to pH 6.8 AßOs were mainly spherical and curvilinear structures, the latter apparently resulting from bead-chain-like association of the spherical $\mathrm{A} \beta \mathrm{Os}^{6}$. At $\mathrm{pH} 6.4, \mathrm{~A} \beta \mathrm{Os}$ showed an increased tendency to form more compact structures, such as annular protofibrils and denser clusters. Below pH 6.0, A $\beta O$ s associated into large clusters, in line with a previous description of $\mathrm{A} \beta 40$ 
aggregates at $\mathrm{pH} 5.8^{52}$. Thus, while the fundamental mechanism of $\mathrm{A} \beta \mathrm{O}$ formation seems to be unaffected by $\mathrm{pH}$ reduction, there is an additional level of particle aggregation involved below $\mathrm{pH} 6.0$.

The second kinetic phase in the ThT time course of $\operatorname{dim} A \beta$ aggregation reports on amyloid fibril formation ${ }^{11}$. It is characterized by a lag-time, which reflects the primary and secondary nucleation events involved in nucleated polymerization ${ }^{14,50}$. In contrast to the acceleration of $\mathrm{A} \beta \mathrm{O}$ formation, the lag-time of amyloid formation did not decrease with decreasing $\mathrm{pH}$. On the contrary, the amyloid fibril formation phase could not be observed within 10 hour experiments at $\mathrm{pH}$ values of 6.8 and below. This can be explained by the inhibition that the rapidly forming $\mathrm{A} \beta \mathrm{Os}$ entail on amyloid formation: First, $\mathrm{A} \beta \mathrm{O}$ s compete for the monomer growth substrate of amyloid fibril growth; second, A $\beta O$ s actively inhibit amyloid fibril growth ${ }^{11}$.

\section{A $\beta O$ assembly of $\mathrm{A} \beta 42$ is enabled under endo-lysosomal conditions}

We investigated if the promotion of $\mathrm{A} \beta \mathrm{O}$ formation at endo-lysosomal $\mathrm{pH}$ is sufficient to also support $\mathrm{A} \beta \mathrm{O}$ formation from $\mathrm{A} \beta 42$ at relevant endo-lysosomal $\mathrm{A} \beta$ concentrations, determined to be well above $2.5 \mu \mathrm{M}^{43}$. At $\mathrm{pH} 7.2$, A $\beta 42$ in the concentration range 1.9-9 $\mu \mathrm{M}$ displayed sigmoidal assembly kinetics typical for amyloid fibril formation (Fig. 7a). In contrast, at $\mathrm{pH} 4.5$ lag-free aggregation occurred at a concentration of $5.4 \mu \mathrm{M}$ and above (Fig. 7b). The change from lag-containing to lag-free conditions at $\mathrm{pH} 4.5$ was accompanied by a switch in aggregate morphology from amyloid fibril networks to large $\mathrm{A} \beta \mathrm{O}$ clusters identical to those observed for $\operatorname{dim} \mathrm{A} \beta$ at endo-lysosomal pH (Fig. 7c,d). This indicates that under endo-lysosomal conditions the local $\mathrm{A} \beta$ concentration can exceed the $\mathrm{COC}$ of $\mathrm{A} \beta \mathrm{O}$ formation, suggesting that endosomes/lysosomes may represent crucial sites of $\mathrm{A} \beta \mathrm{O}$ formation in vivo.

$\mathrm{A} \beta$ aggregates can leak from endosomes/lysosomes into the cytosol and to other cell compartments or can be secreted and spread to other cells, potentially contributing to the propagation of $\mathrm{A} \beta$ pathology $26,27,43,44,49$. Upon transfer from endosomes/lysosomes to the 
cytosol or interstitial fluid, $\mathrm{A} \beta \mathrm{O}$ s experience a shift from acidic to neutral $\mathrm{pH}$. We tested the kinetic stability of $\mathrm{A} \beta \mathrm{O}$ s formed at $\mathrm{pH} 4.5$ after a shift to neutral $\mathrm{pH}$ by monitoring the ThT intensity and by imaging the aggregate morphology by AFM. We applied $A \beta 42$ at a concentration of $10 \mu \mathrm{M}$ in this experiment, as $\mathrm{A} \beta 42$ does not form $\mathrm{A} \beta \mathrm{O}$ s de novo at this concentration at neutral $\mathrm{pH}$. Any $\mathrm{A} \beta \mathrm{Os}$ observed after the $\mathrm{pH}$ shift can therefore safely be ascribed to the kinetic stability of $\mathrm{A} \beta \mathrm{Os}$ pre-formed under acidic conditions. As before, a $\mathrm{pH}$ shift from basic $\mathrm{pH}$ to $\mathrm{pH} 4.5$ was applied to initiate $\mathrm{A} \beta \mathrm{O}$ formation. After $\mathrm{A} \beta \mathrm{O}$ formation had reached a steady state, $\mathrm{pH}$ was adjusted to 7.2 by a further injection of a corresponding buffer stock. After the adjustment to neutral $\mathrm{pH}$, there was an instantaneous increase in ThT fluorescence (Supplementary Fig. 6), which can be explained by the $\mathrm{pH}$ dependence of ThT fluorescence ${ }^{62}$. Thereafter, the ThT fluorescence did not exhibit any other larger changes that would be expected in the case of disassembly of $A \beta O$ s or replacement of $A \beta O$ s by an alternative type of aggregate. Apart from dense clusters like those observed for low $\mathrm{pH}$ A $\beta \mathrm{Os}$, AFM images showed spherical and curvilinear structures typical for $\mathrm{A} \beta \mathrm{O}$ s formed at neutral $\mathrm{pH}$, indicating dissociation of the $\mathrm{A} \beta \mathrm{O}$ clusters into their constituents (Fig. 8a). In fact, the AFM images suggest that smaller $\mathrm{A} \beta \mathrm{O}$ s detach from fraying $\mathrm{A} \beta \mathrm{O}$ clusters. Taken together, the ThT and AFM data demonstrate that $\mathrm{A} \beta \mathrm{O}$ s formed at endo-lysosomal $\mathrm{pH}$ possess a high kinetic stability after shifting to neutral $\mathrm{pH}$, which is, however, accompanied by dissociation of large $\mathrm{A} \beta \mathrm{O}$ clusters into spherical and curvilinear A $\beta$ Os.

\section{Discussion}

$\mathrm{A} \beta \mathrm{O}$ s have been identified as the main neurotoxic $\mathrm{A} \beta$ species in $\mathrm{AD}$. The characterization of the most critical disease-related $\mathrm{A} \beta \mathrm{O}$ s has revealed that they are metastable oligomers $>50$ $\mathrm{kD}$ in size that do not represent intermediates of amyloid fibril formation but are an alternative $\mathrm{A} \beta$ assembly type. However, the conditions required for $\mathrm{A} \beta \mathrm{O}$ formation and the underlying 
mechanism have not been elucidated in detail. Here, we show that $\mathrm{A} \beta \mathrm{O}$ formation is highly $\mathrm{pH}-$ dependent, and is accelerated $\sim 8,000$-fold upon a change in $\mathrm{pH}$ from neutral to endo-lysosomal $\mathrm{pH}$. This enables $\mathrm{A} \beta \mathrm{O}$ formation at physiologically relevant $\mathrm{A} \beta$ concentrations. The strong acceleration of $\mathrm{A} \beta \mathrm{O}$ formation at $\mathrm{pH} 4.5-5.5$ suggests that the endosomal/lysosomal system might be a major site of $\mathrm{A} \beta \mathrm{O}$ formation. $\mathrm{A} \beta \mathrm{O}$ s may either form from $\mathrm{A} \beta$ monomers that have been newly generated by APP processing or from endocytosed monomers (Fig. 8b) ${ }^{39-41,43,46,47}$. APP processing in endo-lysosomal compartments by $\gamma$-secretase containing presenilin 2 generates a prominent pool of intracellular $A \beta$ that is enriched in $A \beta 42$ (ref. ${ }^{47}$ ). Esbjörner et al. applied fluorescence lifetime and superresolution imaging to determine the kinetics of $\mathrm{A} \beta$ aggregation in live cells and found that aggregation occurred in endo-lysosomal compartments $^{40}$. Importantly, they reported that $\mathrm{A} \beta 42$ aggregated without a lag-time into compact, dense structures ${ }^{40}$. Both the absence of a lag-time and the structural characterization are in line with the low $\mathrm{pH} A \beta \mathrm{O}$ clusters described here, suggesting that $\mathrm{A} \beta \mathrm{O}$ clusters indeed form in endo-lysosomal compartments and represent the dominant $A \beta$ aggregate species in live cells. Subsequently, AßOs might cause lysosomal impairment, leak into the cytosol and cause intracellular damage, or might be secreted and spread to neighboring cells, where they could contribute to the propagation of pathology $39,41,43-45,47$.

Enhanced aggregation at acidic $\mathrm{pH}$ is a known property of $\mathrm{A} \beta$ with established relevance for sample preparation ${ }^{61}$. Our results are in line with a study on the aggregation of $A \beta 40$ (at a concentration of $230 \mu \mathrm{M}$ ) at $\mathrm{pH} 5.8$ that reported the rapid formation of large clusters with (proto)fibrillar and globular substructures that were not able to seed, but rather inhibited, amyloid fibril formation ${ }^{52}$. Our analysis of the aggregation kinetics reveals that these low $\mathrm{pH}$ A $\beta$ aggregates, often termed amorphous aggregates, form along the same pathway as neutral $\mathrm{pH} \mathrm{A} \beta \mathrm{Os}$ and therefore represent particle aggregates of $\mathrm{A} \beta \mathrm{Os}$. This is supported by the observation that low $\mathrm{pH} \mathrm{A} \beta \mathrm{O}$ clusters release spherical and curvilinear $\mathrm{A} \beta \mathrm{Os}$ upon a shift to neutral pH (Fig. 8a). 
The increasing clustering of $\mathrm{A} \beta \mathrm{O}$ s upon $\mathrm{pH}$ reduction from neutral to $\mathrm{pH} 6$ points to the high propensity of $\mathrm{A} \beta \mathrm{Os}$ to associate. At neutral $\mathrm{pH}$, self-association of spherical $\mathrm{A} \beta \mathrm{O}$ s results in curvilinear assemblies. A decrease of $\mathrm{pH}$ leads to an increase in annular and compact assemblies and finally to large $\mathrm{A} \beta \mathrm{O}$ clusters (Fig. 6). This propensity of $\mathrm{A} \beta \mathrm{O}$ s to associate likely also contributes to their clustering with neuronal receptors ${ }^{34,35}$ and to their accumulation around amyloid fibril plaques ${ }^{63}$.

In contrast to $A \beta O$ formation, amyloid fibril formation of $\operatorname{dim} A \beta$ is slowed down at acidic $\mathrm{pH}$. This $\mathrm{pH}$ dependence is not an inherent property of $\mathrm{A} \beta$ amyloid fibril formation: In the absence of $\mathrm{A} \beta \mathrm{Os}, \mathrm{A} \beta 42$ amyloid fibril formation occurs rapidly at $\mathrm{pH} 4.5$ (Fig. 7b, $1.9 \mu \mathrm{M}$ trace). Delayed amyloid fibril formation upon $\mathrm{pH}$ reduction is only observed in combination with accelerated $\mathrm{A} \beta \mathrm{O}$ formation, and can be explained by the two inhibitory activities of $\mathrm{A} \beta \mathrm{Os}$ on amyloid fibril formation: AßOs compete with amyloid fibrils for monomers (Fig. 1a) and furthermore inhibit amyloid fibril growth actively ${ }^{11}$.

$\operatorname{DimA} \beta$ A $\beta$ Os show dendritic spine binding, lack direct cytotoxicity, potently induce Tau missorting, and decrease neuronal activity, suggesting that they constitute a suitable $\mathrm{A} \beta \mathrm{O}$ model construct to study the pathomechanism of AD. Previous A $\beta O$ preparations showed a loss of potency to induce Tau missorting within 12 hours due to transformation to non-toxic larger $\mathrm{A} \beta$ $\operatorname{aggregates}^{37,60}$. In contrast, $\operatorname{dim} \mathrm{A} \beta \mathrm{A} \beta \mathrm{Os}$ led to extensive and persistent Tau missorting $24 \mathrm{~h}$ after application. The sustained activity of $\operatorname{dim} A \beta A \beta O s$ is likely a consequence of the kinetic stabilization of the $\mathrm{A} \beta \mathrm{O}$ state achieved by the dimer linkage. $\operatorname{DimA} \beta$ might therefore be an advantageous model for eliciting Tau missorting and downstream consequences, as it represents a model of chronic stress corresponding to the human disease rather than acute insult. 


\section{Methods}

\section{Preparation of $\operatorname{dim} A \beta$}

$\operatorname{DimA} \beta$ was recombinantly produced as previously described ${ }^{11}$. For aggregation kinetics experiments, the lyophilized protein was reconstituted in $6 \mathrm{M}$ guanidinium chloride, $50 \mathrm{mM}$ sodium-phosphate buffer, $\mathrm{pH} 7.4$, and incubated at room temperature for $30 \mathrm{~min}$. Subsequently, SEC was performed using a Superdex 75 increase column (GE Healthcare) equilibrated with 1 $\mathrm{mM} \mathrm{NaOH}$. The concentration of the monomeric $\operatorname{dim} \mathrm{A} \beta$ in the alkaline eluate was measured via tyrosine fluorescence using a $\mathrm{pH}$-adjusted extinction coefficient of $2685 \mathrm{M}^{-1} \mathrm{~cm}^{-1}$. Samples were always kept on ice until further needed.

\section{ThT aggregation kinetics}

ThT, $\mathrm{NaN}_{3}, \mathrm{NaCl}$, protein, and $1 \mathrm{mM} \mathrm{NaOH}$ were given into the wells of a 96-well low-binding plate (Greiner) such that if filled up to $100 \mu \mathrm{L}$, concentrations of $1 \mu \mathrm{M}$ ThT, $0.02 \% \mathrm{NaN}_{3}$, $150 \mathrm{mM} \mathrm{NaCl}$, and the desired final protein concentration were reached. The outermost wells of the plate were left blank due to the risk of aberrant aggregation behavior. The plate was put in a BMG ClarioStar platereader fitted with two injectors and tempered at $37^{\circ} \mathrm{C}$. One syringe of the injector was equilibrated with $1 \mathrm{~mL} \mathrm{10x}$ buffer concentrate. The reaction was started using the injector of the platereader by dispensing $10 \mu \mathrm{L}$ of the concentrate at highest available speed into each of the wells. This adjusted the $\mathrm{pH}$ value in situ and initiated oligomerization. Data points were measured in evenly spaced intervals depending on the velocity of the reaction. For shifting the $\mathrm{pH}$ in situ twice, both syringes were equilibrated with 10x buffer concentrate; the first one resulting in a final buffer concentration of $20 \mathrm{mM}$ and $\mathrm{pH} 4.5$ and the second one resulting in a final buffer concentration of $50 \mathrm{mM}$ and $\mathrm{pH}$ 7.2. The first syringe was used to inject $10 \mu \mathrm{l}$ to initiate oligomerization, whereas the second one was used to inject $11 \mu \mathrm{l}$ to 
achieve the shift to neutral $\mathrm{pH}$ at a time point were the oligomerization reaction had reached its plateau.

For analysis of the kinetics of $\mathrm{A} \beta \mathrm{O}$ formation, the initial phase of the ThT kinetics was fit to one-step oligomerization $n \mathrm{M} \rightarrow \mathrm{M}_{\mathrm{n}}$ (ref. ${ }^{11}$ ). The $\mathrm{A} \beta \mathrm{O}$ mass concentration, $M_{A \beta O}$, evolves in time according to the following expression

$$
M_{A \beta O}(t)=M_{0}-\left[M_{0}^{1-n}+(n-1) n k t\right]^{1 /(1-n)}
$$

with $M_{0}$ the total protein concentration, $k$ the oligomerization rate constant, and $n$ the oligomer size or reaction order. Global fits to the $\mathrm{pH}$ - and concentration-dependent $\mathrm{A} \beta \mathrm{O}$ formation data were performed with a reaction order of $n=3$ shared between all data sets, and the oligomerization rate constant $k$ as a $\mathrm{pH}$-dependent parameter which was shared within the concentration dependency data sets at a given $\mathrm{pH}$. The proportionality constant relating $M(\mathrm{t})$ to ThT fluorescence intensity was treated as a fit parameter with an individual value for every sample.

\section{Atomic force microscopy (AFM)}

$10 \mu \mathrm{l}$ of the $\operatorname{dimA} \beta$ samples were taken directly from the plate after the ThT assays at a concentration of $5 \mu \mathrm{M}$ and applied onto freshly cleaved muscovite mica. They were left to dry,

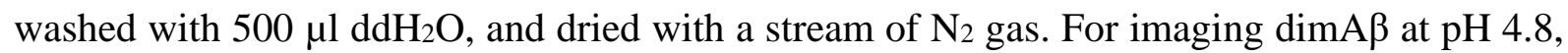
the aforementioned method did not work, likely due to sticking of the sample to the well. Instead, all reaction components apart from the buffer concentrate were premixed and loaded into a micro pipette tip. By adding the reaction components to a vial containing the buffer concentrate and thorough mixing, the reaction was started, before pulling the solution back into the tip. Immediately afterwards, the micropipette was relocated into a $37^{\circ} \mathrm{C}$ incubation cabinet, where a drop was pushed out to the point where it still stuck to the tip. After $45 \mathrm{sec}$, the drop was pushed onto the freshly cleaved muscovite mica and preparation commenced as with the other $\mathrm{pH}$ values. 
For the $A \beta 42$ samples, $5 \mu 1$ of the respective concentrations were taken, applied onto freshly cleaved muscovite mica and left to dry for 15 min before carefully washing with $200 \mu 1$ $\mathrm{ddH}_{2} \mathrm{O}$ and drying under a stream of $\mathrm{N}_{2}$ gas.

Imaging was performed in intermittent contact mode (AC mode) in a JPK Nano Wizard 3 atomic force microscope (JPK, Berlin) using a silicon cantilever with silicon tip (OMCLAC160TS-R3, Olympus) with a typical tip radius of $9 \pm 2 \mathrm{~nm}$, a force constant of $26 \mathrm{~N} / \mathrm{m}$ and resonance frequency around $250 \mathrm{kHz}$. The images were processed using JPK DP Data Processing Software (version spm-5.0.84). For the presented height profiles a polynomial fit was subtracted from each scan line first independently and then using limited data range. Falsecolor height images were overlaid onto the amplitude profile.

\section{Cryo-EM}

For cryo-EM imaging, the $\mathrm{A} \beta \mathrm{O}$ sample was plunge-frozen on glow-discharged Quantifoil 1.2/1.3 grids. In total 1308 micrographs were recorded as focal pairs at high defocus $(6 \mu \mathrm{m})$ and low defocus (using a range of -0.5 to $-2 \mu \mathrm{m}$ ) on a Tecnai Arctica (200 kV) using a Falcon III direct electron detector, yielding a pixel size of $0.935 \AA$. Particle selection was performed automatically using crYOLO ${ }^{64}$. In total 32,211 particles were selected on the high defocus micrographs. The contrast transfer function (CTF) of the micrographs was determined using CTFFIND $4^{65}$. Further image processing was performed using the software package RELION 3.0.5 $.2 \mathrm{D}$ and $3 \mathrm{D}$ classification was conducted on the high defocus images to clean the dataset. A box size of 128 pix, which corresponds to $119.7 \AA$, and a radial mask with a diameter of 100 Å were used.

The high-defocus micrographs were aligned to the low-defocus micrographs. The relative shifts obtained from this alignment were applied to all particles (that were picked from the highdefocus micrographs) and then the particles were extracted from the low-defocus micrographs with the shifted particle coordinates, while keeping the Euler angles from the high-defocus 3D 
refinements. A 3D reconstruction calculated from the high defocus images was low-pass filtered to $60 \AA$ and was used as an initial model for further low-defocus 3D refinements. For further processing steps only micrographs that contain a signal beyond a resolution of $5 \AA$ were used. The final resolution of $17 \AA$ was assessed by Fourier shell correlation.

In order to obtain an estimate for the molecular mass within the reconstructed density, 110 pseudo-atomic models with varying number of pseudo-atoms (molecular masses between 10 and $120 \mathrm{kDa}$ ) were generated from the density map using the program $\mathrm{VISDEM}^{67}$, which is part of the software package DireX ${ }^{68}$. In VISDEM, atoms are randomly placed into a density region with density above a provided threshold. The density threshold was set to yield a volume such that the mass density is fixed at $0.714 \mathrm{ml} / \mathrm{g}$ (average mass density observed in proteins). The pseudo-atomic model has a composition of $62.2 \% \mathrm{C}$ atoms, $20.6 \% \mathrm{O}$ atoms and $17.2 \% \mathrm{~N}$ atoms, which corresponds to the average composition observed in proteins. Afterwards, a density map was computed from every of the 110 pseudo-atomic models. The VISDEM method was used to sharpen these pseudo-atomic model-maps as well as the EM reconstruction. The sharpening was performed with a resolution cutoff of $17 \AA$ and the mass of the corresponding pseudo-atomic model. Finally, the cross-correlation between the sharpened EM reconstruction and the sharpened pseudo-atomic model-map was computed and plotted for each tested mass. The highest cross-correlation was found for the pseudo-atomic model-map that contains a molecular mass of $62 \mathrm{kDa}$. One $\operatorname{dim} \mathrm{A} \beta$ monomer (101 amino acids) has a molecular mass of $10.0 \mathrm{kDa}$. Thus, the reconstructed density likely holds $6 \operatorname{dim} \mathrm{A} \beta$ monomers. The final 3D reconstruction of the oligomer was sharpened by VISDEM using a mass of $62 \mathrm{kDa}$ and a resolution cutoff of $17 \AA$.

\section{$A \beta$ preparations and treatment of primary neurons}

$A \beta$ preparations were performed under sterile conditions. DimA $\beta$ lyophilisate was resuspended in $50 \mathrm{mM} \mathrm{NaOH}$ until completely dissolved. Next, PBS and $50 \mathrm{mM} \mathrm{HCl}$ were added and 
immediately mixed, obtaining a final concentration of $20 \mu \mathrm{M} \operatorname{dim} \mathrm{A} \beta$ and $40 \mu \mathrm{M} \mathrm{A} \beta 40$, respectively. To induce $\mathrm{A} \beta \mathrm{O}$ formation, $\operatorname{dim} \mathrm{A} \beta$ was incubated at $37^{\circ} \mathrm{C}$ for 16 hours. $\mathrm{A} \beta 40$ controls were prepared in the same manner without subsequent incubation. Primary neurons (DIV15-22) were treated with either $0.5 \mu \mathrm{M} \operatorname{dim} \mathrm{A} \beta \mathrm{A} \beta \mathrm{O}$ or $1 \mu \mathrm{M} \mathrm{A} \beta 40$ monomers diluted in conditioned neuronal maintenance media for 3 and 24 hours under growth conditions. In addition, cells were treated with a vehicle control (PBS containing $50 \mathrm{mM} \mathrm{NaOH}$ and $50 \mathrm{mM}$ $\mathrm{HCl})$. Afterwards cells were fixed and stained as described before ${ }^{69}$.

\section{Primary neuron culture}

Primary neurons were isolated and cultured as described before ${ }^{69}$ with slight modifications. In brief, brains of FVB/N mouse embryos were dissected at embryonic day 13.5. Brainstem and meninges were removed and whole cortex was digested with 1x Trypsin (Panbiotech). Neurons were diluted in pre-warmed $\left(37^{\circ} \mathrm{C}\right)$ neuronal plating medium (Neurobasal media (Thermofisher Scientific), 1\% FBS, 1x Antibiotic-/Antimycotic solution (Thermofisher Scientific), 1x NS21 (Panbiotech)) and cultivated in a humidified incubator at $37^{\circ} \mathrm{C}, 5 \% \mathrm{CO}_{2}$. Four days after plating, media was doubled with neuronal maintenance media (Neurobasal media (Thermofisher Scientific), 1x Antibiotic-/Antimycotic solution (Thermofisher Scientific), 1x NS21 (Panbiotech)) and cells were treated with $0.5 \mu \mathrm{g} / \mathrm{ml}$ AraC (Sigma).

\section{Immunofluorescence staining and data analysis}

Somatodendritic missorting of Tau - To analyze Tau somatodendritic localization, cells were fixed and stained with a polyclonal rabbit anti-Tau (K9JA, Dako A0024) antibody after A $\beta$ treatment as described before ${ }^{69}$. Fluorescence intensities of cell bodies were quantified using ImageJ software ${ }^{70,71}$. Fluorescence intensity values were normalized to vehicle treated control cells after 3 hours of treatment. All experiments were performed four times; 30 cells were 
analyzed for each condition. Statistical analysis was done by two-way ANOVA with Tukey's test for multiple comparisons.

Cytotoxic effect of $\operatorname{dim} A \beta$ - To evaluate $\mathrm{A} \beta \mathrm{O}$ toxicity, cells were fixed and stained with NucBlue (Thermofisher Scientific) after $\operatorname{dim} \mathrm{A} \beta \mathrm{A} \beta \mathrm{O}$ treatment. Shape and density of nuclei were analyzed and counted: Cells were considered dead, when nuclei appeared condensed and smaller, compared to viable cell nuclei. All experiments were conducted for four times; around 300 nuclei were analyzed for each condition. Statistical analysis was done by two-way ANOVA with Tukey's test for multiple comparisons.

A $\beta$ targeting to postsynaptic spines and calcium imaging - To analyze A $\beta$ binding to synapses, neurons were fixed and stained for F-actin with phalloidin (Thermofisher Scientific) and a monoclonal mouse anti-A $\beta$ (clone 4G8, Merck, \#MAB1561) antibody. To monitor spontaneous $\mathrm{Ca}^{2+}$ oscillations, primary neurons were labelled with Fluo-4 (Thermofisher Scientific) and Pluronic F127 (Merck) for 20 minutes after 24 hours of $\operatorname{dimA} \beta$ treatment. Time-lapse movies of different fields were recorded for 1 minute each (framerate: 1 second). Fluorescence intensity changes of cell bodies were quantified over time with Image ${ }^{70,71}$ and corrected for background signal. Fluorescence intensities were normalized to minimum values and peaks per minute were counted for each sample. In total 35 cells were analyzed; statistical analysis was done by unpaired t-test.

\section{Preparation of fluorescently labeled $A \beta$ for cell culture experiments}

Preparation of AbberiorStar 520SXP-labeled CysO-dimA $\beta$ - A mutant of $\operatorname{dimA} \beta$ with an $\mathrm{N}-$ Terminal cysteine residue was expressed as described above. For fluorophore-labeling, TCEPreduced Cys0-dimA $\beta$ lyophilisate was incubated in 200mM HEPES pH 7.0 with a two-fold molar excess of maleimide-conjugated AbberiorStar 520SXP fluorophore, which was dissolved in DMF. After $2 \mathrm{~h}$ of incubation the labeled $\operatorname{dim} A \beta$ was purified using reverse-phase HPLC. 
Samples were lyophilized, redissolved in HFIP and aliquots were prepared. These aliquots were lyophilized and stored at RT for later use.

Preparation of Aß42-HiLyte Fluor 647 for cell culture experiments - Aß42-HiLyte Fluor 647 (Anaspec) was dissolved in HFIP and lyophilized into smaller aliquots $(30 \mu \mathrm{g})$. For cell culture experiments aliquots were first dissolved in $3 \mu 150 \mathrm{mM} \mathrm{NaOH}$. $544 \mu \mathrm{l}$ phenol red-free DMEM supplemented with $100 \mathrm{U} / \mathrm{ml}$ penicillin-streptomycin was added and the $\mathrm{pH}$ was recalibrated by the addition of $3 \mu \mathrm{l} 50 \mathrm{mM} \mathrm{HCl}$. To avoid exposure of the $\mathrm{A} \beta$ peptide to local low $\mathrm{pH}$ environments, the $\mathrm{HCl}$ was pipetted into the lid of the tube, closed and quickly vortexed. This procedure yields a $10 \mu \mathrm{M}$ mostly monomeric stock solution of A $\beta 42-H i L y t e$ Fluor 647 suitable for cell culture experiments.

Preparation of AbberiorStar 520SXP-dimA $\beta$ ABOs for cell culture experiments - Abberior STAR 520SXP-labeled A $\beta$ Os were prepared by dissolving a 1:10 molar ratio of Abberior STAR 520SXP-labeled $\operatorname{dim} A \beta$ and unlabeled $\operatorname{dimA} \beta$ in $10 \mu 150 \mathrm{mM} \mathrm{NaOH}$. Quickly, $490 \mu 1$ phenol red-free DMEM supplemented with $100 \mathrm{U} / \mathrm{ml}$ penicillin-streptomycin was added and the $\mathrm{pH}$ readjusted by adding $10 \mu 150 \mathrm{mM} \mathrm{HCl}$. The final $\operatorname{dimA} \beta$ concentration was $10 \mu \mathrm{M}$. The sample was quiescently incubated at $37^{\circ} \mathrm{C}$ in the dark for $24 \mathrm{~h}$. A $\beta \mathrm{O}$ formation was confirmed using AFM. We were unable to produce large amounts of Abberior STAR 520SXP-labeled $\operatorname{dim} A \beta$, therefore unlabeled $\operatorname{dim} A \beta$ was spiked with labeled $\operatorname{dim} A \beta$ to achieve concentrations above the COC.

\section{Neuroblastoma cell culture}

SH-SY5Y cells were grown to 80\% confluency in DMEM with phenol red, $10 \%$ FBS, and 100 U/ml penicillin-streptomycin in T75 flasks. Experiments were performed in Ibidi collagen IV coated $\mu$-Slide VI 0.4 . 7,500 cells $(250,000$ cells $/ \mathrm{ml})$ were seeded into each channel of the slide. Cells adhered to the surface of the channels within an hour of incubation at $37^{\circ} \mathrm{C}, 5 \% \mathrm{CO}_{2}$, in a humidified chamber. Subsequently, the feeding reservoirs of the channels were filled with 
further medium. Each day, the medium in the reservoirs was replaced with fresh medium until the cell density was satisfactory for coincubation experiments.

\section{Coincubation experiments and imaging}

For coincubation and imaging experiments phenol red was removed by flushing the channels three times with phenol red-free DMEM supplemented with $100 \mathrm{U} / \mathrm{ml}$ penicillin-streptomycin. Subsequently, channels were filled with medium containing corresponding A $\beta$ species. Cells were incubated for 24 hours. Channels were flushed with fresh medium and supplemented with $50 \mathrm{nM}$ Yellow HCK-123 LysoTracker. Imaging was performed either on a Leica Infinity TIRF microscope or on a confocal microscope. Confocal measurements were performed using a TCS SP8 STED 3× (Leica Microsystems) equipped with an HC PL APO CS2 100× objective (NA 1.4) at a scan speed of $600 \mathrm{~Hz}$ and a line accumulation of $6.488 \mathrm{~nm}$ of a pulsed white light laser was chosen as excitation for Yellow HCK-123 LysoTracker and AbberiorSTAR520XPS. The emitted fluorescent signal was detected by counting-mode hybrid detectors in the spectral range of $500-531 \mathrm{~nm}$ for Yellow HCK-123 LysoTracker and $650-765 \mathrm{~nm}$ for AbberiorStar520SXP. Additionally, a time-gating of $0.1 \mathrm{~ns}$ was used to avoid laser reflection. 


\section{References}

1. Gremer, L. et al. Fibril structure of amyloid- $\beta(1-42)$ by cryo-electron microscopy. Science 358, 116-119 (2017).

2. Kollmer, M. et al. Cryo-EM structure and polymorphism of A $\beta$ amyloid fibrils purified from Alzheimer's brain tissue. Nat Commun 10, 4760 (2019).

3. Selkoe, D.J. \& Hardy, J. The amyloid hypothesis of Alzheimer's disease at 25 years. EMBO Mol. Med. 8, 595-608 (2016).

4. Cline, E.N., Bicca, M.A., Viola, K.L. \& Klein, W.L. The Amyloid- $\beta$ oligomer hypothesis: Beginning of the third decade. J. Alzheimer's Dis. 64, S567-S610 (2018).

5. Ono, K. \& Tsuji, M. Protofibrils of amyloid- $\beta$ are important targets of a disease-modifying approach for Alzheimer's disease. Int. J. Mol. Sci. 21(2020).

6. Chromy, B.A. et al. Self-assembly of A $\beta(1-42)$ into globular neurotoxins. Biochemistry 42 , 12749-12760 (2003).

7. Jan, A., Hartley, D.M. \& Lashuel, H.A. Preparation and characterization of toxic A $\beta$ aggregates for structural and functional studies in Alzheimer's disease research. Nat. Protoc. 5, 1186-1209 (2010).

8. Lambert, M.P. et al. Diffusible, nonfibrillar ligands derived from A $\beta 1-42$ are potent central nervous system neurotoxins. Proc. Natl. Acad. Sci. U. S. A. 95, 6448-6453 (1998).

9. Walsh, D.M. et al. Amyloid $\beta$-protein fibrillogenesis. Structure and biological activity of protofibrillar intermediates. J. Biol. Chem. 274, 25945-25952 (1999).

10. Walsh, D.M., Lomakin, A., Benedek, G.B., Condron, M.M. \& Teplow, D.B. Amyloid $\beta$-protein fibrillogenesis. Detection of a protofibrillar intermediate. J. Biol. Chem. 272, 22364-22372 (1997).

11. Hasecke, F. et al. Origin of metastable oligomers and their effects on amyloid fibril selfassembly. Chem. Sci. 9, 5937-5948 (2018).

12. Bitan, G., Fradinger, E.A., Spring, S.M. \& Teplow, D.B. Neurotoxic protein oligomers--what you see is not always what you get. Amyloid 12, 88-95 (2005).

13. Kodali, R. \& Wetzel, R. Polymorphism in the intermediates and products of amyloid assembly. Curr. Opin. Struct. Biol. 17, 48-57 (2007).

14. Cohen, S.I. et al. Proliferation of amyloid- $\beta 42$ aggregates occurs through a secondary nucleation mechanism. Proc. Natl. Acad. Sci. U. S. A. 110, 9758-9763 (2013).

15. Sehlin, D. et al. Large aggregates are the major soluble A $\beta$ species in AD brain fractionated with density gradient ultracentrifugation. PLoS One 7, e32014 (2012).

16. Fowler, S.W. et al. Genetic modulation of soluble $A \beta$ rescues cognitive and synaptic impairment in a mouse model of Alzheimer's disease. J. Neurosci. 34, 7871-7885 (2014).

17. Lacor, P.N. et al. A $\beta$ oligomer-induced aberrations in synapse composition, shape, and density provide a molecular basis for loss of connectivity in Alzheimer's disease. J. Neurosci. 27, 796807 (2007).

18. Forny-Germano, L. et al. Alzheimer's disease-like pathology induced by amyloid- $\beta$ oligomers in nonhuman primates. J. Neurosci. 34, 13629-13643 (2014).

19. Hartley, D.M. et al. Protofibrillar intermediates of amyloid $\beta$-protein induce acute electrophysiological changes and progressive neurotoxicity in cortical neurons. J. Neurosci. 19, 8876-8884 (1999).

20. Yasumoto, T. et al. High molecular weight amyloid $\beta 1-42$ oligomers induce neurotoxicity via plasma membrane damage. FASEB J. 33, 9220-9234 (2019).

21. Klyubin, I. et al. Soluble Arctic amyloid $\beta$ protein inhibits hippocampal long-term potentiation in vivo. Eur. J. Neurosci. 19, 2839-2846 (2004). 
22. Tomiyama, T. et al. A mouse model of amyloid $\beta$ oligomers: their contribution to synaptic alteration, abnormal tau phosphorylation, glial activation, and neuronal loss in vivo. J. Neurosci. 30, 4845-4856 (2010).

23. De Felice, F.G. et al. A $\beta$ oligomers induce neuronal oxidative stress through an N-methyl-Daspartate receptor-dependent mechanism that is blocked by the Alzheimer drug memantine. $J$. Biol. Chem. 282, 11590-11601 (2007).

24. Maezawa, I., Zimin, P.I., Wulff, H. \& Jin, L.W. Amyloid- $\beta$ protein oligomer at low nanomolar concentrations activates microglia and induces microglial neurotoxicity. J. Biol. Chem. 286, 3693-3706 (2011).

25. Paranjape, G.S., Gouwens, L.K., Osborn, D.C. \& Nichols, M.R. Isolated amyloid- $\beta(1-42)$ protofibrils, but not isolated fibrils, are robust stimulators of microglia. ACS Chem. Neurosci. 3, 302-311 (2012).

26. Söllvander, S. et al. Accumulation of amyloid- $\beta$ by astrocytes result in enlarged endosomes and microvesicle-induced apoptosis of neurons. Mol. Neurodegener. 11, 38 (2016).

27. Umeda, T. et al. Intraneuronal amyloid $\beta$ oligomers cause cell death via endoplasmic reticulum stress, endosomal/lysosomal leakage, and mitochondrial dysfunction in vivo. J. Neurosci. Res. 89, 1031-1042 (2011).

28. Zempel, H. \& Mandelkow, E. Lost after translation: missorting of Tau protein and consequences for Alzheimer disease. Trends Neurosci. 37, 721-732 (2014).

29. Lord, A. et al. Amyloid- $\beta$ protofibril levels correlate with spatial learning in Arctic Alzheimer's disease transgenic mice. FEBS J. 276, 995-1006 (2009).

30. Tomiyama, T. et al. A new amyloid $\beta$ variant favoring oligomerization in Alzheimer's-type dementia. Ann. Neurol. 63, 377-387 (2008).

31. Kutzsche, J. et al. Safety and pharmacokinetics of the orally available antiprionic compound PRI002: A single and multiple ascending dose phase I study. Alzheimers Dement (N Y) 6, e12001 (2020).

32. Logovinsky, V. et al. Safety and tolerability of BAN2401--a clinical study in Alzheimer's disease with a protofibril selective A $\beta$ antibody. Alzheimers Res. Ther. 8, 14 (2016).

33. Overk, C.R. \& Masliah, E. Toward a unified therapeutics approach targeting putative amyloid- $\beta$ oligomer receptors. Proc. Natl. Acad. Sci. U. S. A. 111, 13680-13681 (2014).

34. Jarosz-Griffiths, H.H., Noble, E., Rushworth, J.V. \& Hooper, N.M. Amyloid- $\beta$ Receptors: The Good, the Bad, and the Prion Protein. J. Biol. Chem. 291, 3174-3183 (2016).

35. Rösener, N.S. et al. A d-enantiomeric peptide interferes with heteroassociation of amyloid- $\beta$ oligomers and prion protein. J. Biol. Chem. 293, 15748-15764 (2018).

36. De Felice, F.G. et al. Alzheimer's disease-type neuronal tau hyperphosphorylation induced by A $\beta$ oligomers. Neurobiol. Aging 29, 1334-1347 (2008).

37. Zempel, H. et al. Amyloid- $\beta$ oligomers induce synaptic damage via Tau-dependent microtubule severing by TTLL6 and spastin. EMBO J. 32, 2920-2937 (2013).

38. Zempel, H., Thies, E., Mandelkow, E. \& Mandelkow, E.M. A $\beta$ oligomers cause localized Ca(2+) elevation, missorting of endogenous Tau into dendrites, Tau phosphorylation, and destruction of microtubules and spines. J. Neurosci. 30, 11938-11950 (2010).

39. LaFerla, F.M., Green, K.N. \& Oddo, S. Intracellular amyloid- $\beta$ in Alzheimer's disease. Nat. Rev. Neurosci. 8, 499-509 (2007).

40. Esbjörner, E.K. et al. Direct observations of amyloid $\beta$ self-assembly in live cells provide insights into differences in the kinetics of $\mathrm{A} \beta(1-40)$ and $\mathrm{A} \beta(1-42)$ aggregation. Chem. Biol. 21, 732-742 (2014).

41. Orr, M.E. \& Oddo, S. Autophagic/lysosomal dysfunction in Alzheimer's disease. Alzheimers Res. Ther. 5, 53 (2013). 
bioRxiv preprint doi: https:/doi.org/10.1101/2020.06.28.175885; this version posted June 28, 2020. The copyright holder for this preprint (which was not certified by peer review) is the author/funder, who has granted bioRxiv a license to display the preprint in perpetuity. It is made available under aCC-BY-NC-ND 4.0 International license.

42. Rushworth, J.V., Griffiths, H.H., Watt, N.T. \& Hooper, N.M. Prion protein-mediated toxicity of amyloid- $\beta$ oligomers requires lipid rafts and the transmembrane LRP1. J. Biol. Chem. 288, 89358951 (2013).

43. $\mathrm{Hu}, \mathrm{X}$. et al. Amyloid seeds formed by cellular uptake, concentration, and aggregation of the amyloid- $\beta$ peptide. Proc. Natl. Acad. Sci. U. S. A. 106, 20324-20329 (2009).

44. Soura, V. et al. Visualization of co-localization in A $\beta 42$-administered neuroblastoma cells reveals lysosome damage and autophagosome accumulation related to cell death. Biochem. J. 441, 579590 (2012).

45. Marshall, K.E., Vadukul, D.M., Staras, K. \& Serpell, L.C. Misfolded amyloid- $\beta-42$ impairs the endosomal-lysosomal pathway. Cell. Mol. Life Sci. (2020).

46. Koo, E.H. \& Squazzo, S.L. Evidence that production and release of amyloid $\beta$-protein involves the endocytic pathway. J. Biol. Chem. 269, 17386-17389 (1994).

47. Sannerud, R. et al. Restricted Location of PSEN $2 / \gamma-$ Secretase Determines Substrate Specificity and Generates an Intracellular A $\beta$ Pool. Cell 166, 193-208 (2016).

48. Lord, A. et al. The Arctic Alzheimer mutation facilitates early intraneuronal A $\beta$ aggregation and senile plaque formation in transgenic mice. Neurobiol. Aging 27, 67-77 (2006).

49. Yang, A.J., Chandswangbhuvana, D., Margol, L. \& Glabe, C.G. Loss of endosomal/lysosomal membrane impermeability is an early event in amyloid A $\beta 1-42$ pathogenesis. J. Neurosci. Res. 52, 691-698 (1998).

50. Meisl, G. et al. Molecular mechanisms of protein aggregation from global fitting of kinetic models. Nat. Protoc. 11, 252-272 (2016).

51. Michaels, T.C.T. et al. Dynamics of oligomer populations formed during the aggregation of Alzheimer's A $\beta 42$ peptide. Nat. Chem. 12, 445-451 (2020).

52. Wood, S.J., Maleeff, B., Hart, T. \& Wetzel, R. Physical, morphological and functional differences between ph 5.8 and 7.4 aggregates of the Alzheimer's amyloid peptide A $\beta . J$. Mol. Biol. 256, 870877 (1996).

53. Barghorn, S. et al. Globular amyloid $\beta$-peptide oligomer - a homogenous and stable neuropathological protein in Alzheimer's disease. J. Neurochem. 95, 834-847 (2005).

54. Gong, Y. et al. Alzheimer's disease-affected brain: presence of oligomeric A $\beta$ ligands (ADDLs) suggests a molecular basis for reversible memory loss. Proc. Natl. Acad. Sci. U. S. A. 100, $10417-$ 10422 (2003).

55. Lesne, S. et al. A specific amyloid- $\beta$ protein assembly in the brain impairs memory. Nature 440, 352-357 (2006).

56. Liu, P. et al. Quaternary Structure Defines a Large Class of Amyloid- $\beta$ Oligomers Neutralized by Sequestration. Cell Rep. 11, 1760-1771 (2015).

57. Morinaga, A. et al. Critical role of interfaces and agitation on the nucleation of A $\beta$ amyloid fibrils at low concentrations of A $\beta$ monomers. Biochim. Biophys. Acta 1804, 986-995 (2010).

58. Carrotta, R., Manno, M., Bulone, D., Martorana, V. \& San Biagio, P.L. Protofibril formation of amyloid $\beta$-protein at low $\mathrm{pH}$ via a non-cooperative elongation mechanism. J. Biol. Chem. 280, 30001-30008 (2005).

59. Zempel, H. \& Mandelkow, E.M. Linking amyloid- $\beta$ and tau: amyloid- $\beta$ induced synaptic dysfunction via local wreckage of the neuronal cytoskeleton. Neurodegenerative Diseases 10, 6472 (2012).

60. Kuperstein, I. et al. Neurotoxicity of Alzheimer's disease $A \beta$ peptides is induced by small changes in the $\mathrm{A} \beta 42$ to $\mathrm{A} \beta 40$ ratio. EMBO J. 29, 3408-3420 (2010).

61. Fezoui, Y. et al. An improved method of preparing the amyloid $\beta$-protein for fibrillogenesis and neurotoxicity experiments. Amyloid 7, 166-178 (2000). 
62. Hackl, E.V., Darkwah, J., Smith, G. \& Ermolina, I. Effect of acidic and basic pH on Thioflavin T absorbance and fluorescence. Eur. Biophys. J. 44, 249-261 (2015).

63. Brody, D.L., Jiang, H., Wildburger, N. \& Esparza, T.J. Non-canonical soluble amyloid- $\beta$ aggregates and plaque buffering: controversies and future directions for target discovery in Alzheimer's disease. Alzheimers Res. Ther. 9, 62 (2017).

64. Wagner, T. et al. SPHIRE-crYOLO is a fast and accurate fully automated particle picker for cryoEM. Communications Biology 2, 218 (2019).

65. Rohou, A. \& Grigorieff, N. CTFFIND4: Fast and accurate defocus estimation from electron micrographs. J. Struct. Biol. 192, 216-221 (2015).

66. Zivanov, J. et al. New tools for automated high-resolution cryo-EM structure determination in RELION-3. Elife 7(2018).

67. Spiegel, M., Duraisamy, A.K. \& Schröder, G.F. Improving the visualization of cryo-EM density reconstructions. J. Struct. Biol. 191, 207-213 (2015).

68. Schröder, G.F., Brunger, A.T. \& Levitt, M. Combining efficient conformational sampling with a deformable elastic network model facilitates structure refinement at low resolution. Structure 15, 1630-1641 (2007).

69. Zempel, H. \& Mandelkow, E.M. Tracking Tau in Neurons: How to Grow, Fix, and Stain Primary Neurons for the Investigation of Tau in All Developmental Stages. Methods Mol. Biol. 1523, 327334 (2017).

70. Schindelin, J. et al. Fiji: an open-source platform for biological-image analysis. Nat. Methods $\mathbf{9}$, 676-682 (2012).

71. Schneider, C.A., Rasband, W.S. \& Eliceiri, K.W. NIH Image to ImageJ: 25 years of image analysis. Nat. Methods 9, 671-675 (2012).

72. Campion, D., Pottier, C., Nicolas, G., Le Guennec, K. \& Rovelet-Lecrux, A. Alzheimer disease: modeling an A $\beta$-centered biological network. Mol. Psychiatry 21, 861-871 (2016).

73. Hu, Y.B., Dammer, E.B., Ren, R.J. \& Wang, G. The endosomal-lysosomal system: from acidification and cargo sorting to neurodegeneration. Translational Neurodegeneration $\mathbf{4}, 18$ (2015).

\section{Acknowledgements}

This project has received funding from the European Research Council under the European Union's Horizon 2020 research and innovation program, grant agreement No. 726368. We acknowledge support from the Hans und Ilse Breuer-Stiftung, the Else-Kröner-Fresenius Stiftung, and Köln Fortune. We acknowledge the Center of Advanced Imaging (CAI) at the Heinrich Heine University Düsseldorf for providing access to the TCS SP8 STED $3 \times$ and support during image acquisition.

Competing interests: The authors declare no competing interests. 
bioRxiv preprint doi: https://doi.org/10.1101/2020.06.28.175885; this version posted June 28,2020 . The copyright holder for this preprint (which was not certified by peer review) is the author/funder, who has granted bioRxiv a license to display the preprint in perpetuity. It is made available under aCC-BY-NC-ND 4.0 International license.
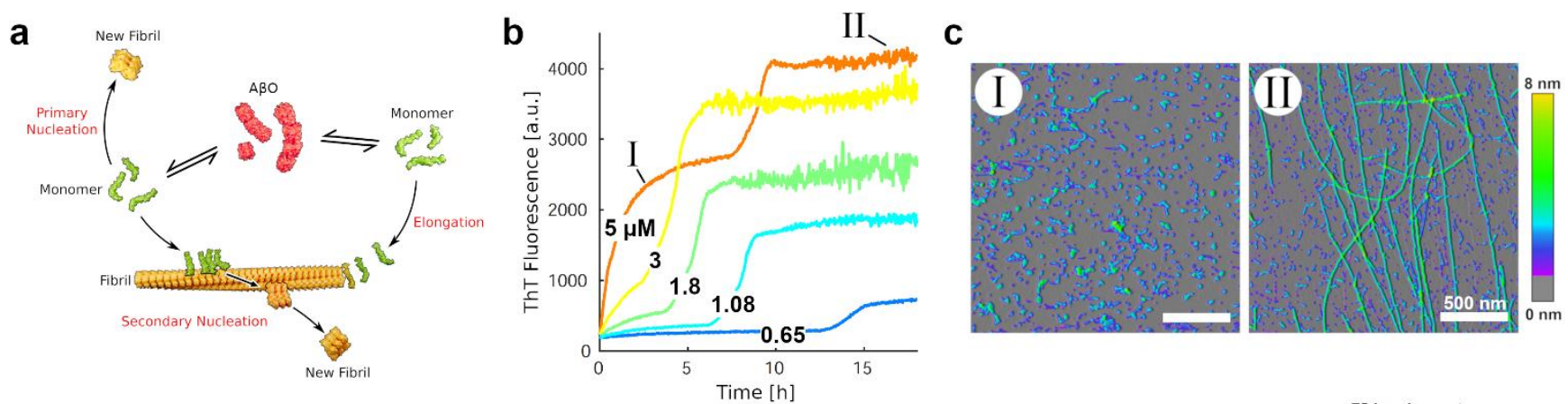

d

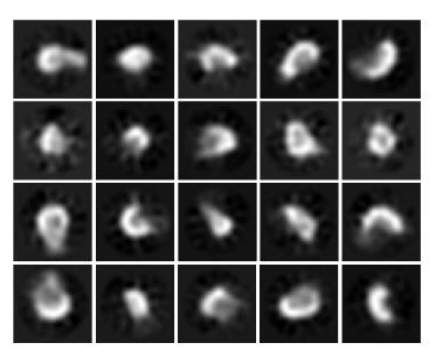

e
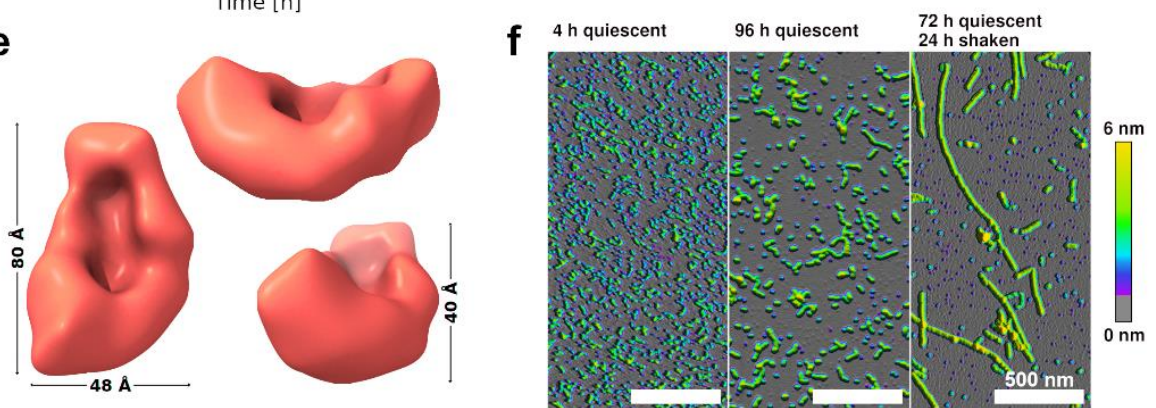

Fig. $1 \mathrm{~A} \beta \mathrm{O}$ s assemble from $\operatorname{dim} A \beta$ in a lag-free oligomerization reaction. a Scheme of $A \beta O$ and amyloid fibril formation. b Biphasic assembly kinetics of $\operatorname{dimA} \beta$ at $\mathrm{pH} 7.4$ and indicated concentrations monitored by ThT fluorescence. c AFM images corresponding to the two kinetic phases. d Exemplary 2D classes of the smallest $\operatorname{dim} \mathrm{A} \beta \mathrm{A} \beta \mathrm{O}$ species observed in cryo-EM micrographs. e 3D density reconstruction of this $\operatorname{dim} A \beta A \beta O$ species at a resolution of $17 \AA$ by cryo-EM. f AFM images of $\operatorname{dimA} \beta$ assemblies formed upon incubation at $\mathrm{pH} 7.4$ in microcentrifuge tubes. 


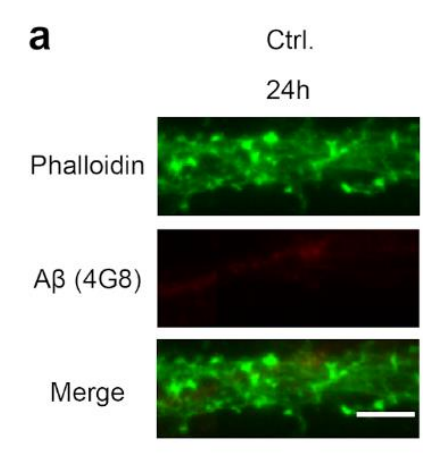

b

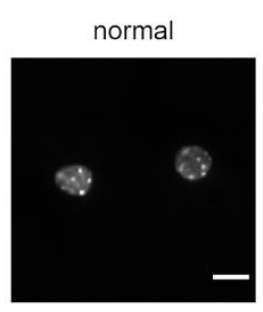

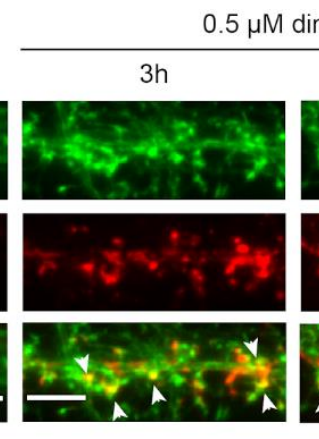
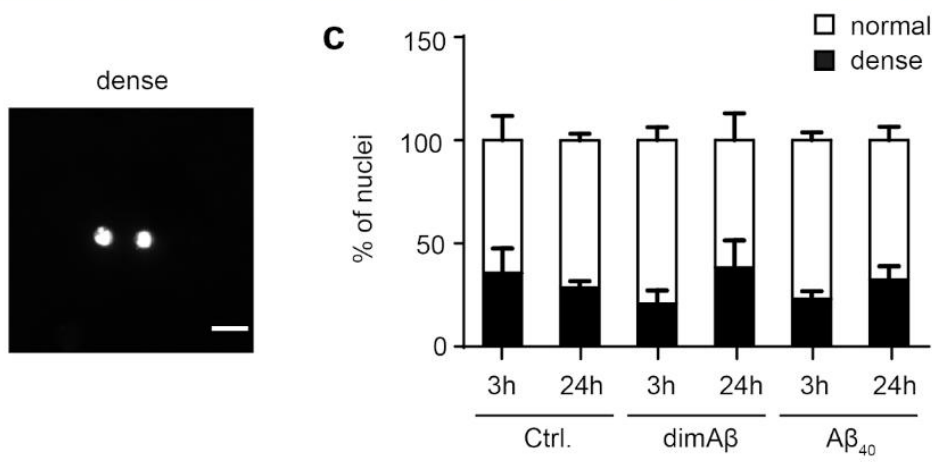

Fig. $2 \operatorname{Dim} A \beta A \beta O$ s bind to dendrites and postsynaptic spines but has no direct cytotoxic effect on primary mouse neurons. Primary mouse neurons (DIV15-22) were treated with 0.5 $\mu \mathrm{M} \operatorname{dim} \mathrm{A} \beta \mathrm{A} \beta \mathrm{Os}$ or $1 \mu \mathrm{M} \mathrm{A} \beta 40$ for 3 and 24 hours. $\mathbf{a} \operatorname{DimA} \beta \mathrm{A} \beta O$ s localized to neuronal dendrites both after 3 and 24 hours of treatment, where they partially co-localized with phalloidin, a marker for synaptic spines. Arrows indicate co-localization of $\operatorname{dim} A \beta$ with phalloidin. Scale bar, $5 \mu \mathrm{m}$. b Nuclei of primary neurons were stained with NucBlue and analyzed with respect to shape and size. Representative images of normal and dense nuclei. Scale bar, $10 \mu \mathrm{m}$. c Quantification of normal and dense nuclei of primary neurons after control, $A \beta 40$, or $\operatorname{dim} \mathrm{A} \beta \mathrm{A} \beta \mathrm{O}$ treatment revealed no direct cytotoxicity. Around 300 nuclei were analyzed for each condition. Error bars represent SEM. Statistical analysis was done by two-way ANOVA with Tukey's test for multiple comparisons. 
a
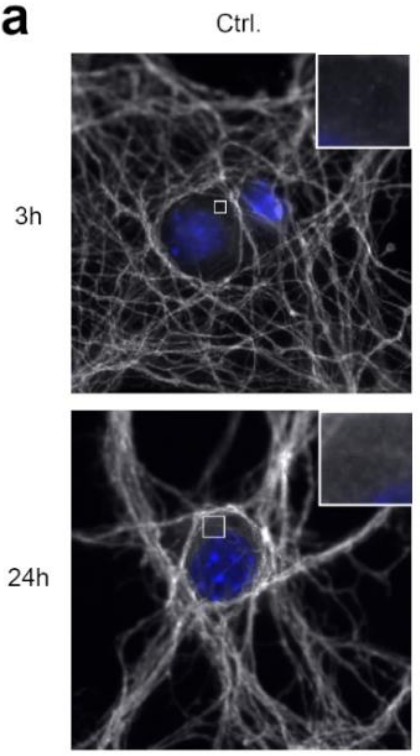

$0.5 \mu \mathrm{M} \operatorname{dim} \mathrm{A} \beta$
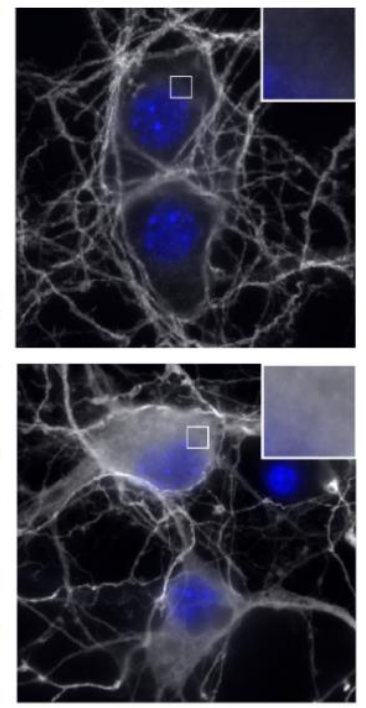

$1.0 \mu \mathrm{MA} \beta_{40}$
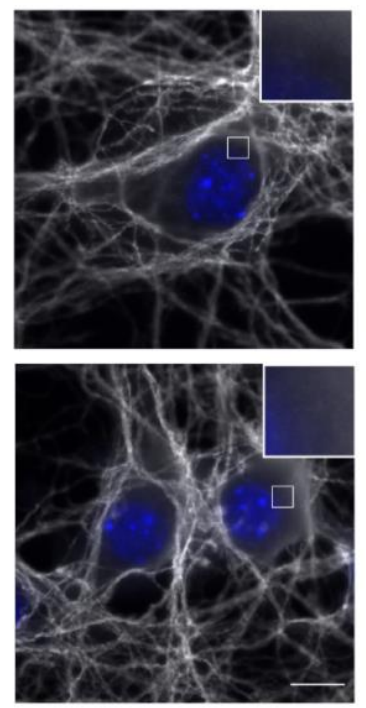

b

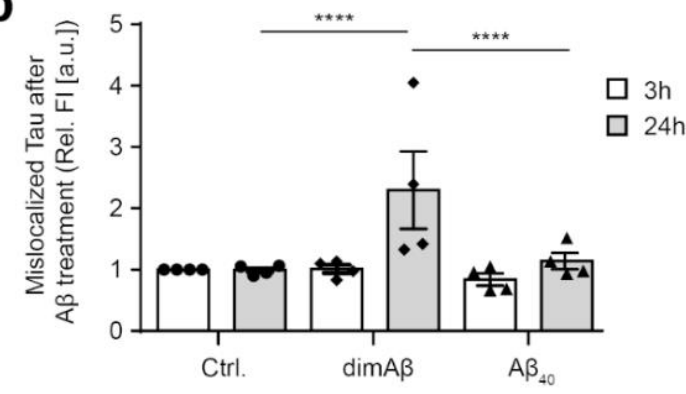

Fig. 3 Dim $A \beta A \beta O$ s induce pathological somatodendritic missorting of Tau. Primary mouse neurons (DIV15-22) were treated with $0.5 \mu \mathrm{M} \operatorname{dim} \mathrm{A} \beta \mathrm{A} \beta \mathrm{Os}$ or $1 \mu \mathrm{M} \mathrm{A} \beta 40$ for 3 and 24 hours. a Representative images of cell bodies of primary neurons after treatment with A $\beta$. Neurons were stained with anti-Tau (K9JA) antibody, nuclei were stained with NucBlue. $\operatorname{DimA} \beta \mathrm{A} \beta \mathrm{O}$ treated neurons show strong enrichment of fluorescence signal of Tau in the soma only after 24 hours of treatment. Insets show magnification of white boxed areas in the somata. Scalebar, $10 \mu \mathrm{m}$. b Quantification of Tau enrichment in the soma of primary neurons. Fluorescence intensities of cell bodies were quantified and normalized to control treated neurons after 3 hours of treatment. $\mathrm{N}=4,30$ cells were analyzed for each condition. Error bars represent SEM. Statistical analysis was done by two-way ANOVA with Tukey's test for multiple comparisons. Statistical significance: $* * * *=p \leq 0.0001$. 
a
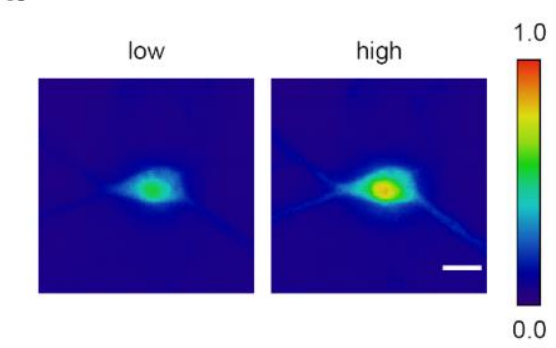

C

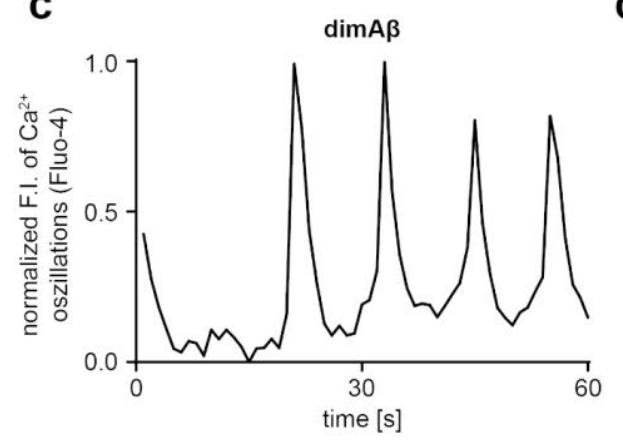

b ctrl.

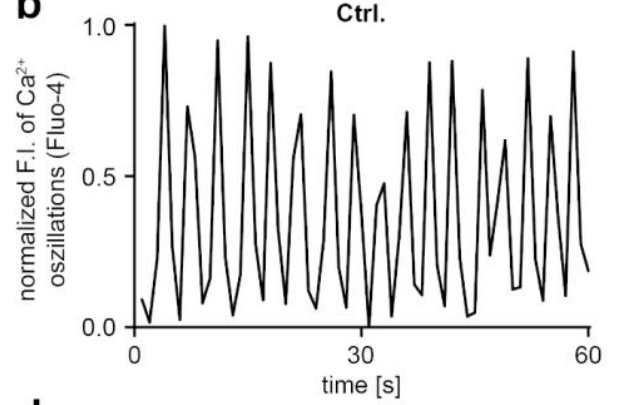

d

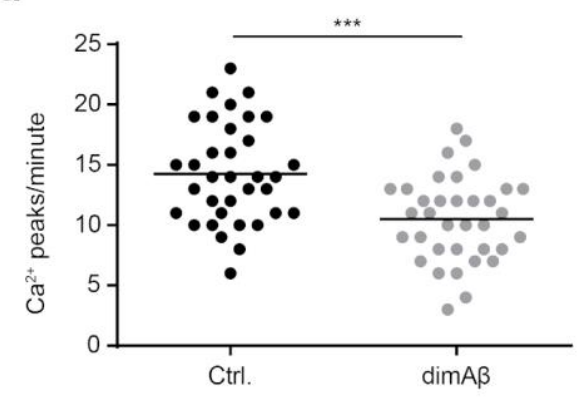

Fig. $4 \operatorname{Dim} A \beta A \beta O s$ decrease spontaneous calcium oscillations of primary mouse neurons.

Primary mouse neurons (DIV15-22) were treated with $0.5 \mu \mathrm{M} \operatorname{dimA} \beta \mathrm{A} \beta \mathrm{Os}$ for 24 hours.

Cells were labelled with calcium-sensitive Fluo-4 dye and spontaneous calcium oscillations were recorded by time-lapse movies. a Representative ratiometric images of low and high calcium concentrations in the soma of a neuron. Scalebar, $20 \mu \mathrm{m} . \mathbf{b}, \mathbf{c}$ Representative graphs of spontaneous $\mathrm{Ca}^{2+}$ oscillations in $\mathbf{b}$ vehicle control and $\mathbf{c} \operatorname{dim} \mathrm{A} \beta \mathrm{A} \beta \mathrm{O}$ treated primary neurons. Fluorescence intensities were normalized to minimum values and plotted over time. d Quantification of spontaneous $\mathrm{Ca}^{2+}$ oscillations in primary neurons after vehicle control or $\operatorname{dim} \mathrm{A} \beta \mathrm{A} \beta \mathrm{O}$ treatment. Fluorescence intensities were normalized to minimum values and peaks per minute were counted for each sample. In total, 35 cells were analyzed; statistical analysis was done by unpaired t-test. Statistical significance: $* * *=p \leq 0.001$. 


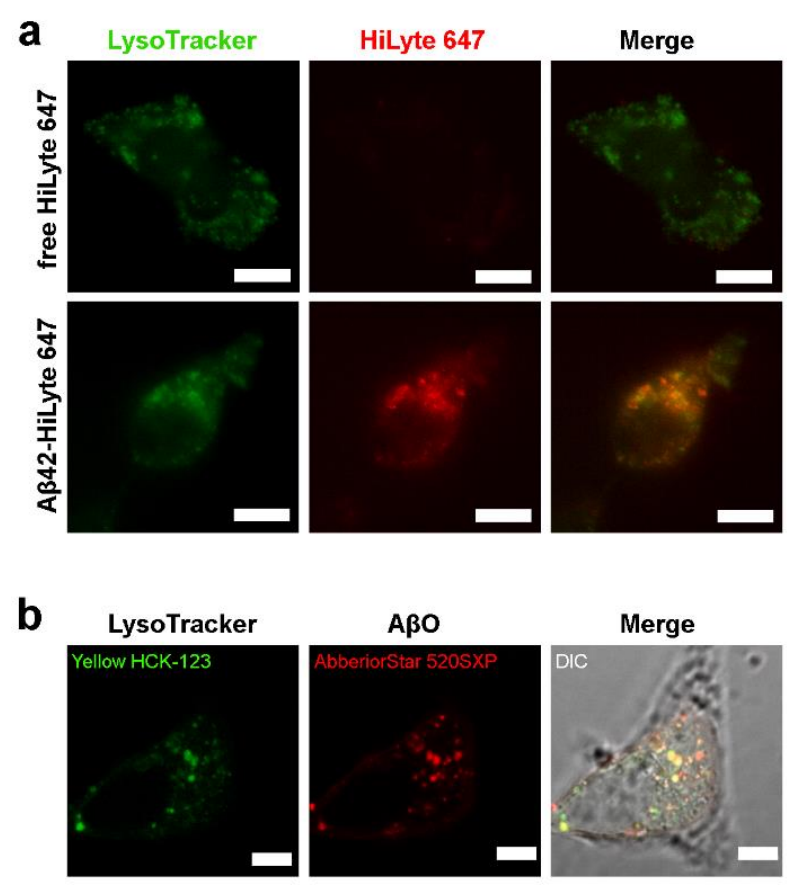

Fig. 5 A $\beta 42$ and $\operatorname{dim} A \beta$ A $\beta O$ s accumulate in endosomes/lysosomes. SH-SY5Y cells were treated with $\mathrm{A} \beta 42$ or $\operatorname{dim} \mathrm{A} \beta$ and co-localization with endo-lysosomal compartments was analyzed. a $0.1 \mu \mathrm{M}$ free HiLyte 647 dye or $0.1 \mu \mathrm{M}$ HiLyte 647 -labeled $\mathrm{A} \beta 42$ was added to the cells. After 24 hours the medium was exchanged with fresh medium supplemented with $50 \mathrm{nM}$ Yellow HCK-123 LysoTracker dye. Scalebar, $10 \mu \mathrm{m}$. b Cells were treated with $\operatorname{dim} A \beta$ A $\beta O s$ $(0.1 \mu \mathrm{M}$ AbberiorStar 520SXP-labeled $\operatorname{dim} A \beta+1 \mu \mathrm{M}$ unlabeled $\operatorname{dim} \mathrm{A} \beta)$. After 24 hours the medium was exchanged with fresh medium supplemented with $50 \mathrm{nM}$ Yellow HCK-123 LysoTracker dye. Scalebar, $5 \mu \mathrm{m}$. 

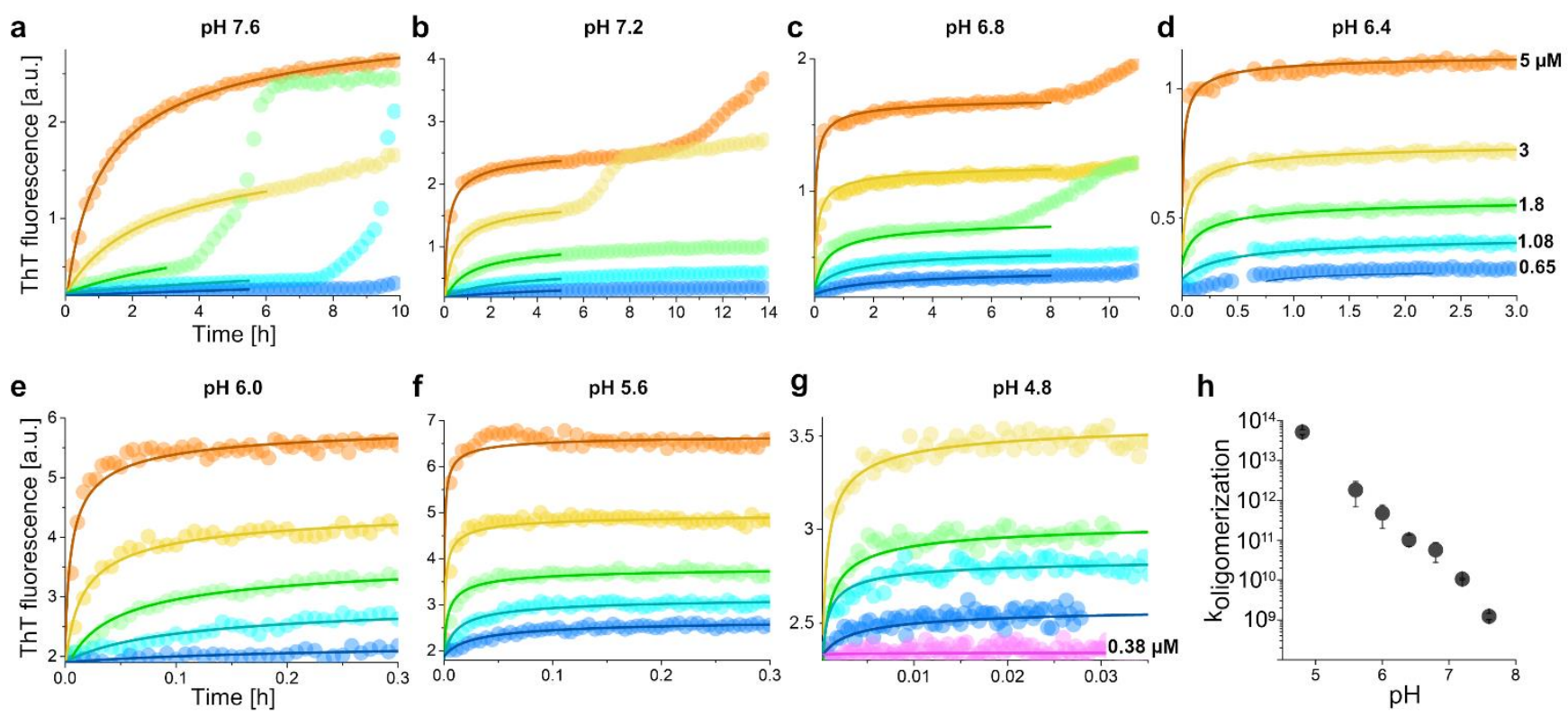

i

pH 7.6

pH 7.2

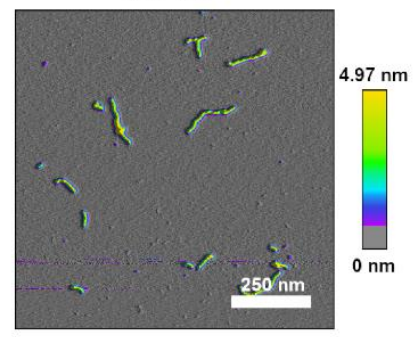

pH 6.0

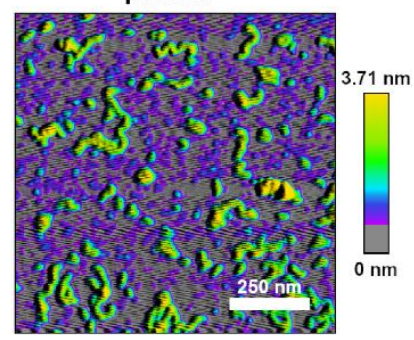

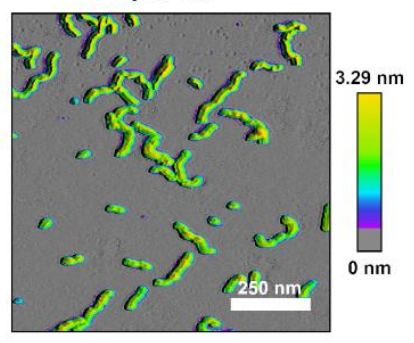

pH 5.6

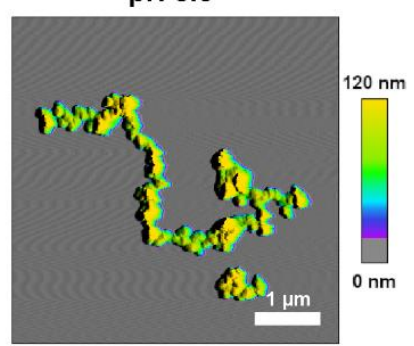

pH 6.8

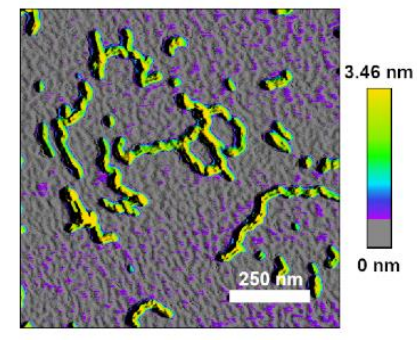

$\mathrm{pH} 4.8$

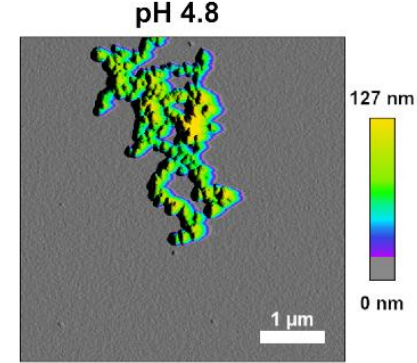

pH 6.4

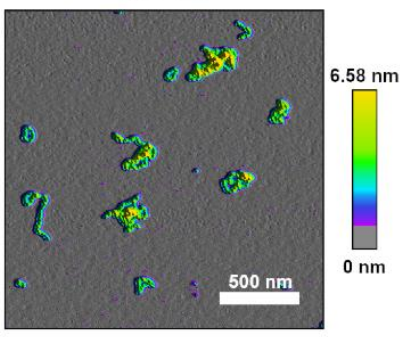

Fig. $6 \mathrm{pH}$ dependence of $\operatorname{dim} \mathrm{A} \beta$ assembly kinetics. a-g $\operatorname{Dim} A \beta$ assembly at concentrations between 0.65 and $5 \mu \mathrm{M}$ and at $\mathrm{pH}$ values between 4.8 and 7.6 monitored by ThT fluorescence. Solid lines represent global fits to the data using a one-step oligomerization model with a shared reaction order of 3 for all $\mathrm{pH}$ values and concentrations, and an individual oligomerization rate constant per $\mathrm{pH}$ value. $\mathbf{h}$ Logarithmic plot of the obtained oligomerization rate constants vs. $\mathrm{pH}$. i AFM images of $\operatorname{dim} \mathrm{A} \beta \mathrm{A} \beta \mathrm{O}$ formed at the different $\mathrm{pH}$ values. Note the dramatic change in the height scale bar upon $\mathrm{pH}$ decrease to $<6.0$ due to formation of large $\mathrm{A} \beta \mathrm{O}$ clusters. 
bioRxiv preprint doi: https://doi.org/10.1101/2020.06.28.175885; this version posted June 28, 2020. The copyright holder for this preprint (which was not certified by peer review) is the author/funder, who has granted bioRxiv a license to display the preprint in perpetuity. It is made available under aCC-BY-NC-ND 4.0 International license.

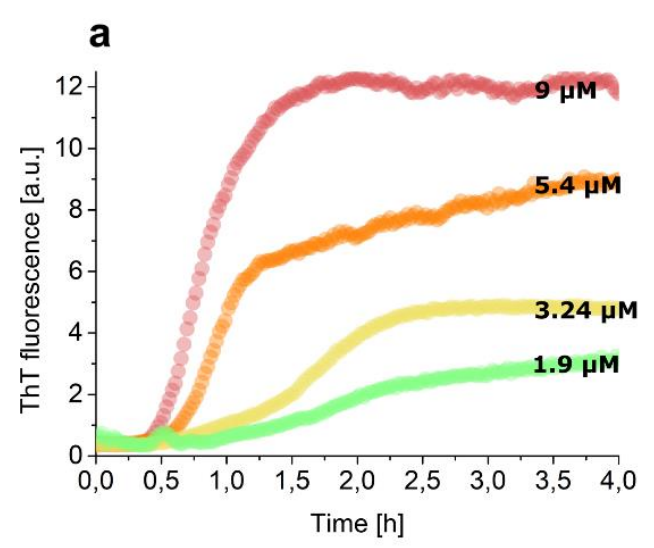

C

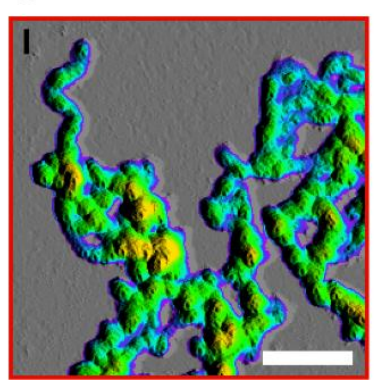

\section{b}

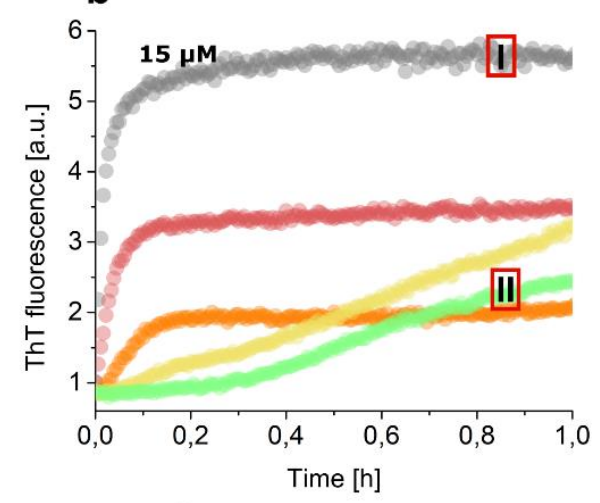

d

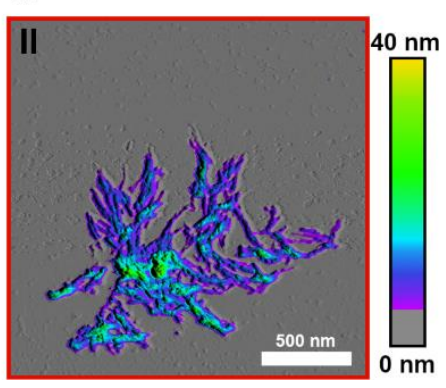

Fig. 7 A $\beta 42$ rapidly forms A $\beta O$ s at endo-lysosomal $\mathrm{pH}$. a, b A $\beta 42$ assembly at a $\mathrm{pH} 7.2$ or b pH 4.5 at concentrations between 1.9 and $15 \mu \mathrm{M}$ monitored by ThT fluorescence. $\mathbf{c}, \mathbf{d}$ AFM images of $\mathbf{c} A \beta O$ s formed of $15 \mu \mathrm{M} \mathrm{A} \beta 42$ and $\mathbf{d}$ amyloid fibril networks formed of $1.9 \mu \mathrm{M}$ $\mathrm{A} \beta 42$, both at $\mathrm{pH} 4.5$. 
bioRxiv preprint doi: https://doi.org/10.1101/2020.06 28.175885; this version posted June 28, 2020. The copyright holder for this preprint (which was not certified by peer review) is the author/funder, who has granted bioRxiv a license to display the preprint in perpetuity. It is made available under aCC-BY-NC-ND 4.0 International license.

\section{a}

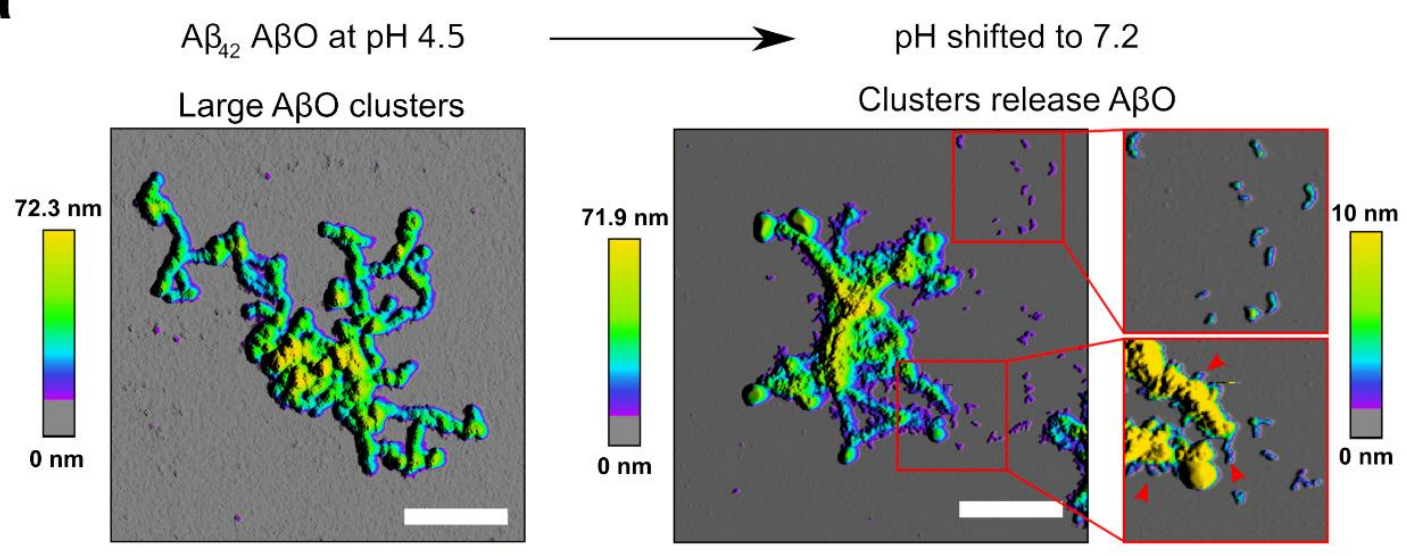

b

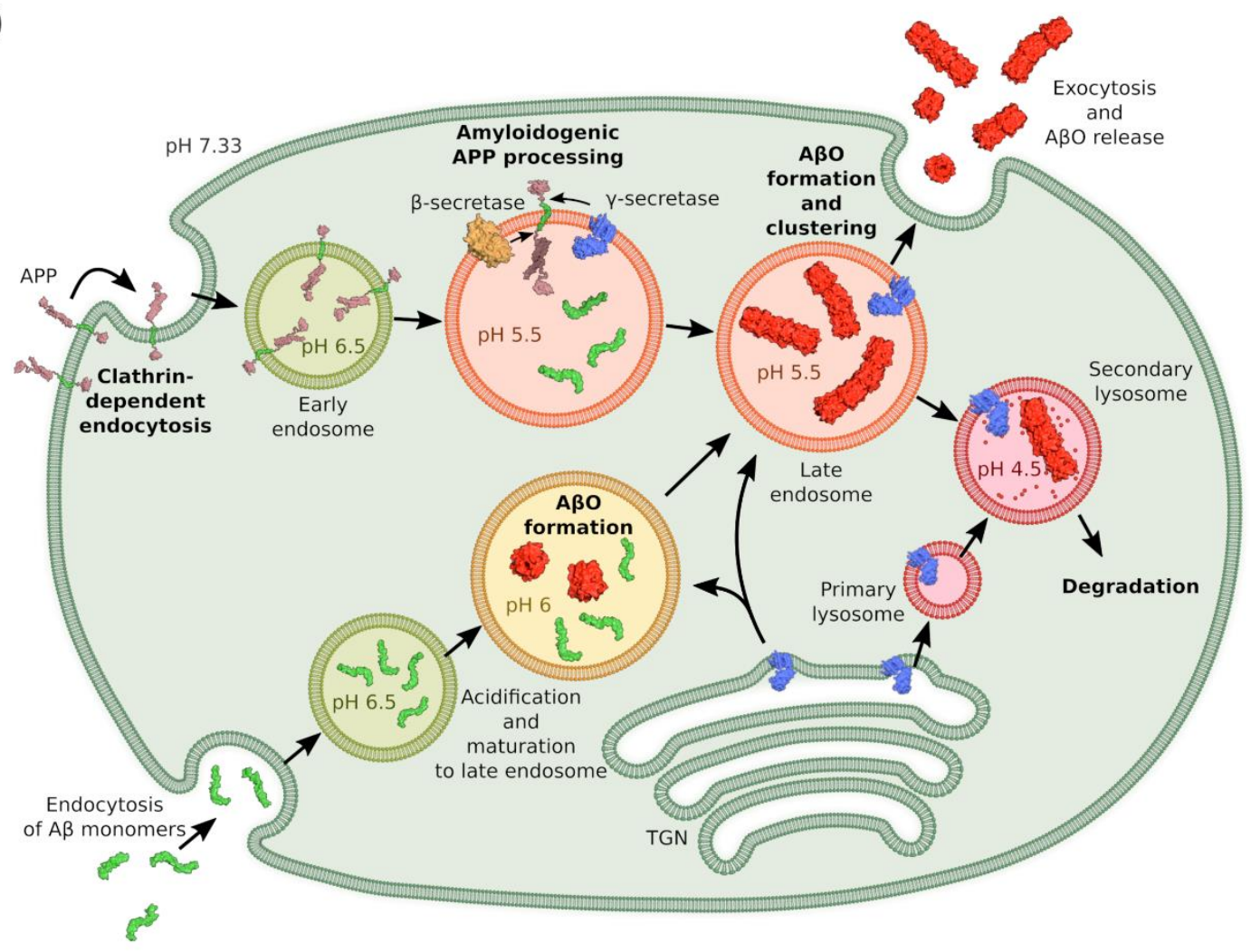

Fig. 8 Stability of $\mathrm{A} \beta \mathrm{O}$ s formed from $\mathrm{A} \beta 42$ at endo-lysosomal $\mathrm{pH}$ after shifting to neutral $\mathrm{pH}$.

a AFM images of $\mathrm{A} \beta \mathrm{O}$ s formed of $10 \mu \mathrm{M} \mathrm{A} \beta 42$ at $\mathrm{pH} 4.5$ before (left) and after (right) shift to $\mathrm{pH}$ 7.2. Red arrowheads point to a few of the sites where $\mathrm{A} \beta \mathrm{O}$ s seem to detach from $\mathrm{A} \beta \mathrm{O}$ clusters. Scalebar, $500 \mathrm{~nm}$. b Scheme of intracellular APP processing and A $\beta$ uptake ${ }^{47,72,73}$, including potential formation of A $\beta O$ s especially in endo-lysosomal compartments. Protein structure images were prepared using pdb entries 1OWT, 1IYT, 1RW6, 3DXC, 4UIS, 1SGZ. 